\title{
Property CRIME DURING THE COVID-19 PANDEMIC: A COMPARISON OF RECORDED OFFENCE RATES AND DYNAMIC FORECASTS (ARIMA) FOR MARCH 2020 IN QUEENSLAND, Australia
}

\author{
A PREPRINT
}

\author{
Jason L. Payne* \\ Centre for Social Research and Methods \\ Australian National University
}

\author{
Anthony Morgan \\ Australian Institute of Criminology
}

May 2020

\begin{abstract}
At the time of writing, there was 3.4 million confirmed cases of COVID-19 and more than 300,000 deaths worldwide. Not since the Spanish Flu in 1918 has the world experienced such a widespread pandemic and this has motivated many countries across globe to take unprecedented actions in an effort to curb the spread and impact of the SARS-CoV-2 virus. Among these government and regulatory interventions includes stringent domestic and international travel restrictions as well as a raft of stay-at-home and social distancing regulations. The scale of these containment measures has left criminologists wondering what impact this will have on crime in both the short- and long-term. In this study, we examine officially recorded property crime rates for March, 2020, as reported for the state of Queensland, Australia. We use ARIMA modeling techniques to compute six-month-ahead forecasts of property damage, shop theft, other theft, burglary, fraud, and motor vehicle theft rates and then compare these forecasts (and their 95\% confidence intervals) with the observed data for March 2020. We conclude that the observed rates of reported property offending across Queensland were significantly lower than expected for shop theft, other theft and credit-card fraud but statistically unchanged for property damage, burglary, and motor-vehicle theft.
\end{abstract}

\section{Introduction}

The World Health Organisation (WHO) declared the novel coronavirus disease 2019 (COVID-19) outbreak, caused by severe acute respiratory syndrome coronavirus-2 (SARS-CoV-2), to be a public health emergency of international concern on 30 January 2020 (World Health Organization, 2020). Since this time, countries around the world have been affected in unprecedented ways. The number of infections has risen quickly, as has the number of deaths attributed to the virus. At the time of writing there was 3.4 million confirmed cases of COVID-19 and more than 300,000 deaths worldwide. An important focus has been on the capacity of the health system in each country to respond to the pandemic. The early experience of China, followed by countries such as Italy, Iran and more recently the United Kingdom and United States, where health systems have quickly become overwhelmed and struggled to cope with the demand from large numbers of infected patients, has motivated countries to take drastic action and implement a wide range of proactive and reactive measures to limit the spread of COVID-19.

Collectively referred to as 'containment measures', these strategies are designed to limit community transmission between individuals. There is, unsurprisingly, a great deal of variation in the ways in which different countries have approached the pandemic, and the types of containment measures they have employed. Despite these differences, each jurisdiction's response has involved some combination of travel restrictions and border controls, quarantine requirements, social isolation and distancing requirements, and the large-scale closure of various services, business, and educational facilities. While the primary concern of government has been to minimise the health impacts of COVID-19, attention has also turned to the other effects of the pandemic. Significant societal and economic impacts have raised questions about potential increases in organised crime (Crime,

\footnotetext{
${ }^{*}$ Corresponding author: jason.payne@anu.edu.au
} 
2020), cybercrime (Europol, 2020) and violent crime (Eisner and Nivette, 2020), particularly domestic violence (Fitz-Gibbon and Meyer, 2020; van Gelder et al., 2020). Conversely, reductions in opportunistic, property crimes have been anticipated (Farrell and Tilley, 2020). The impact of COVID-19 on law enforcement (Lum et al., 2020), courts (Rossner and Tait, 2020; Sarat, 2020) and correctional systems (Kinner et al., 2020) have also been the subject of speculation and analysis. Here the focus has been primarily on the emerging health risks and the impact of containment measures on how these agencies and systems operate.

Some of these changes are likely take longer than others to materialise. But the containment measures have had an immediate impact on the routine activities of individuals, fundamentally changing the way in which people move around (or don't) and come together (or not) in different settings. That is why scholars have quickly turned their attention to the impact on property crime. In the longer term, the additional strain by these containment measures, which have resulted in widespread job losses and lost income, and likely created a high degree of anxiety and stress, might lead to increased involvement in delinquent or criminal behaviour. Understanding these impacts is important to inform how to respond, particularly as the pandemic and containment measures are likely to persist for some time yet.

In this study, we use officially recorded police data from Queensland, Australia, to look for early signs that property crime has changed in the context of the COVID-19 pandemic. In an international context, Australia is a unique site of analysis because the rapid introduction of strong social distancing regulations has coincided with the transition to winter-a time when seasonal crime rates are already expected to fall. Without accounting for these seasonal effects, there is a risk that any observed short-term decline in crime may be overstated and wrongly attributed as a consequence of COVID-19. Similarly, the absence of change or a small and seemingly insignificant increase could be overlooked at a time when crime would normally be expected to decline. In this study, we examine officially recorded property crime rates for the month of March 2020. We conduct this analysis in Queensland because it was the first state or territory in Australia to declare a public health emergency. It was also the first jurisdiction to provide open access to up-to-date data.

\subsection{What restrictions have been introduced in Australia?}

Compared with other countries, the infection rate in Australia has remained relatively low. The first Australian case was recorded in January, however, the number of new cases increased rapidly during March (Figure 1). There have been 6,720 confirmed cases recorded in Australia (as of 27 April) and, so far, 83 people have died as a result of the disease (Australian Government Department of Health, 2020). Most confirmed cases acquired their infection during overseas travel, or via contact with someone who had travelled overseas, and on-board cruise ships (Australian Government Department of Health, 2020).

[Figure 1 about here.]

Importantly, as a federated nation, responsibility for implementing containment measures is shared between the Federal and state and territory governments, while states and territories are able to choose how to enforce them. Although there has been a strong emphasis on a consistent national approach, there has also been variation in some of the measures employed in each jurisdiction. This has included strategies such as border controls and school closures.

Containment measures have been introduced incrementally. In terms of a national response, the entry of foreign nationals from mainland China was banned on 1 February, before incremental travel bans on Iran, South Korea, and Italy in early March. This was followed by self-isolation requirements on all travellers arriving in Australia introduced on 16 March. Large, nonessential, organised public gatherings of more than 500 people were also restricted from this date, as were indoor gatherings of more than 100 people. At the same time, social distancing requirements were introduced, which required individuals to maintain a distance of 1.5 metres from one another. The Biosecurity (Human Biosecurity Emergency) (Human Coronavirus with Pandemic Potential) Declaration 2020 was announced on 18 March, followed by a further announcement that Australian borders were closed to all non-Australian citizens and non-residents effective 20 March. The following day, the requirement that there be 4 square metres per person in any enclosed space was introduced. On the $22 \mathrm{March}$, the Prime Minister announced large-scale closures of on-premise licensed premises, restaurants and cafes (except for takeaway), entertainment venues and places of worship, which took effect the following day. Further restrictions were imposed on a range of other venues, including indoor and outdoor markets, on 26 March, while limits were placed on the number of people who are allowed to attend weddings and funerals. Public gatherings were limited to two people (non-family members) from $30 \mathrm{March}$, and Australians were advised that they were only allowed to leave home for essential shopping, medical needs, exercise, or for work or education.

Queensland became the first Australian state or territory to declare a public health emergency under the Public Health Act 2005 on 29 January. Since the non-essential business, activity and undertaking closure direction was first released on 23 March a series of revisions have been made in line with national requirements, imposing further limits on which venues and businesses may continue to operate. School closures came into effect on 30 March, remaining open to the children of essential service workers. Queensland borders were closed effective $26 \mathrm{March}$, with entry limited to Queensland residents, residents of border communities undertaking essential activities and other exempt persons. Non-residents were initially required to self-isolate for 
14 days after crossing the border; however, as of early April, restrictions were tightened further and only Queensland residents could cross the border. These restrictions are enforceable by law.

\subsection{Why is property crime likely to be impacted by COVID-19?}

These containment measures, particularly those which relate to social distancing requirements, aim to prevent the spread of the virus by restricting the movement of people in the community. This necessary public health measure has a profound impact on people's day to day use of public and private space. The scale of these changes is such that it is plausible to expect that they will also have a measurable impact on crime, in this case property crime.

According to Cohen and Felson's (1979) routine activity theory, crime is more likely to occur when there is a convergence of three critical elements. These are a motivated offender, a suitable target, and the absence of a capable guardian. Crime pattern theory combines aspects of the routine activity approach with other environmental criminological theories and focuses on how offenders may come across opportunities for crime in the course of their everyday lives (brantingham criminality ${ }^{\bullet} \mathbf{1 9 9 3}$ ). Brantingham and Brantingham (1995) describe crime as an even that occurs when the activity spaces of offenders-which concentrate around the places they visit most frequently-intersect with the activity spaces of a target, precipitated by some triggering event. A great deal of property crime is opportunistic in nature. For example, research has shown that most burglary offenders happen across opportunities in the course of their everyday activities, rather than necessarily actively seeking out targets. Obviously, major disruptions of these routine activities may have a significant impact on when, and where, we might expect crime to occur.

Of course, crime is not evenly distributed across place or time. Brantingham and Brantingham (1995) also identified the significance of crime attractors and crime generators. Crime generators are those places that attract large numbers of people, which provide opportunities for targets and offenders to come together in space and time. places... Shopping centres and public transport are both examples of crime generators.

Crime attractors are places that are attractive to motivated offenders because they provide opportunities for crime to occur. Examples include certain licensed premises in the night-time economy, major large-scale shopping centres, poorly secured car parks and drug markets. Because of their crime generating and crime attracting properties, these are common hotspots, including for property crime. Many of these location types have all been profoundly impacted by containment measures. Because they are crime hotspots, these changes to routine activities might be expected to have a disproportionate impact in terms of their share of any crime effects.

Importantly, it would appear that containment measures have indeed had a significant, measurable impact on routine activities of Australians. When asked, adult Australians have reported a high degree of compliance with recommended social distancing practices, including keeping distance between people, avoiding public spaces, and avoiding large gatherings (Australian Bureau of Statistics, 2020b). Further, Google's (2020) mobility data highlights how much peoples' movement and time spent in public and private spaces has changed as a result of various containment measures. Location data reported by Google on community mobility, for example, has tracked how often and for how long people travel to different location types, compared with a baseline value (the median value for the same day of the week in January and early February). Figure 2 shows these changes over time, and demonstrates that there have been significant reductions in visits to public spaces, including parks (down $33 \%$ as of midApril), retail and recreation premises (down 37\%), workplaces (down 39\%) and transit stations (down 59\%). Conversely, the time spent in residential locations has increased by 20 percent.

\section{[Figure 2 about here.]}

Figure 3 describes the trend as at the end of March for Australia, overall, and for Queensland. This shows that the trends observed nationally were not as pronounced in Queensland, but the degree of change in mobility nevertheless indicates a significant in mobility and routine activities. It is possible, however, that these changes occur too late in the month to significantly influence monthly crime rates, analysed in the current study. That significant shift in mobility were observed in March, seemingly in advance of the introduction of major restrictions, indicates that people changed their behaviour in response to the perceived threat from the pandemic before measures were formally implemented. This is not unique to Australian residents; similar patterns have been observed elsewhere, where residents-informed by the risk of infection-engaged in social distancing before the measures announced by government were implemented (Midoes, 2020). However, most of the changes take effect in the second half of March and are sustained through to mid-April. Limiting the amount of time that people are permitted to spend outside of the home, and the number of people outside the home with whom people may have contact, reduces the likelihood of interactions between potential offenders and criminal opportunities.

[Figure 3 about here.]

In light of these findings, it is possible to outline a number of hypotheses about the expected impact on property crime. In practice, the impact is likely to vary by both crime type and by setting. Limiting the amount of time that people are permitted 
to spend outside of the home, and the number of people outside the home with whom people may have contact, reduces opportunities for interactions between potential victims (or targets) and motivated offenders. This is particularly relevant to those crime types that might often occur largely as a consequence of these interactions, particularly theft offences. Consider, for example, the would-be offender who happens across an unattended bag in a train station, or the unattended vehicles in an open-air car park.

Then there is the closure of certain premises, most notably entertainment venues, restaurants and cafes, both as a direct requirement of government policies, or as an indirect consequence of the economic impacts of social distancing (e.g. stores that have closed because customer numbers are down or because the store cannot safely meet the social distancing requirements). This might be expected to significantly impact those offences that occur in these settings; namely, shop stealing offences. In those stores that continue to operate, there has been a notable increase in security and retail staff to manage compliance with social distancing and ensure shelves are restocked, respectively. These may act as place managers and deter offenders who target these open stores.

At the same time, in some locations - primarily residential settings - there will be a marked increase in guardianship because people are confined to their homes. We know that the presence of guardianship has an important influence of offenders' decisions to target certain properties. Normally, this guardianship varies considerably over the course of the day, which shapes when crime is most likely to occur (Reynald and Elffers, 2015). Residential burglary, and other property crimes in residential settings, including vehicle theft and theft from vehicles, may be expected to decline. Conversely, commercial premises are likely to become more susceptible to crime, given the fall in guardianship that coincides with the closures of businesses.

There are other crime types for which the impact is likely to be far more depending on the unique characteristics of subcategories of offences. For example, in the case of property damage, alcohol-related property damage that occurs within the context of the night time economy may decrease, while graffiti and vandalism in public spaces may increase due to reduced surveillance and increased opportunity (less time spent at work or in school). Likewise, there has been growing concern about the impact of COVID-19 on fraud offending, as profit-motivated offenders look to exploit opportunities in weakly controlled financial systems, and the fear and anxiety that might make individuals susceptible to scams. Conversely, offences involving 'tap and go' and online fraud using stolen credit cards may become more difficult, as offenders are no longer able to steal these cards to commit a fraud offence, or then (in the case of 'tap and go' fraud) have limited options in terms of stores to target (for the reasons explained above).

Of course, not everyone will comply with social distancing measures. Unsurprisingly, there is some overlap between the profile of those people who are less likely to comply and those people who are more likely to be involved in crime. Specifically, Nivette et al., (2020) found that non-compliance was associated with antisocial potential, including delinquent behaviour. It is plausible that these non-compliant individuals will be more likely to offend, reducing any effect from the changes to routine activities of compliant individuals.

In the longer-term, it is possible that changes to routine activities become less influential—particularly as containment measures are relaxed-but that the pandemic will lead to an increase in motivated offenders. There is already evidence of the negative psychological impacts of quarantine measures and the other financial consequences resulting from the economic impacts of COVID-19.

Although using the principles of Routine Activity Theory we might expect a significant downside impact in crime throughout the period of social isolation and containment, other factors, such as the unemployment, under-employment, and the General Strain associated with the significant and mounting financial pressures may have the reverse effect (Agnew, 1992). We do not expect these effects to coincide. Instead, it is likely that any upside pressure on crime rates which result from the strain of the economic downturn will not materialise immediately nor suddenly, and may not be apparent in the data until well after the containment measures have been lifted.

Nevertheless, there are already signs of the strain on Australian households. One in three Australian households already report being financially worse off (Australian Bureau of Statistics, 2020b). Levels of anxiety are also much higher than usually observed (Australian Bureau of Statistics, 2020b). The Australian Bureau of Statistics (2020a) reported that 72 percent of businesses have experienced a reduced cash-flow that is expected to harm business activity and employment over the coming months. In fact, throughout March, these challenging economic circumstances have resulted in a 7.5 percent decrease in employee jobs and an 8.2 percent reduction in wages paid to employees (Australian Bureau of Statistics, 2020c). Unsurprisingly some employees and sectors have been harder hit than others, with a 33 percent reduction in employee jobs for the accommodation and food services sector and a 27 percent reduction for the arts and recreation sector. The impact of these will need to be monitored beyond the short-term focus of this paper. 


\subsection{What trends have been observed around the world?}

Despite the significant disruption associated with containment measures, analyses of the crime impact of COVID-19—of which there are a growing number-have tended to find smaller than expected reductions in property crimes. Mohler et al. (2020) analysed daily counts of calls for service and recorded crime in Los Angeles and Indianapolis for several major offence categories. They compared the period after stay at home orders had been issued (March 20 and March 24, respectively)—regard as the time period when full social distancing came into effect- to the period prior to school closures. In terms of property crime, there were significant declines in burglary and robbery calls for service in Los Angeles, and a small increase in vehicle theft, but no change in Indianapolis. However, even where differences in call volumes were observed, they were relatively small in practical terms. Similar trends were observed in recorded crime, but only robbery in Los Angeles was significantly reduced. These findings were reinforced in a second regression that incorporated Google mobility data.

Campedelli et al. (2020) analysed daily recorded crime counts over a three-year period in Los Angeles using Bayesian structural time-series models, incorporating controls for weather (seasonality) and holiday periods. This approach allowed them to produce a synthetic counterfactual - what would have occurred had there been no containment measures — which they compared with observed crime counts during a period of increasingly stringent social distancing measures in March. Property crimes, including shoplifting and thefts, decreased, as did crime overall, and these trends were amplified during the period of more stringent measures.

Most recently, Ashby (2020) analysed data for 16 large US cities. Similar to Campedelli (2020), Ashby forecasted the expected frequency of crime during the pandemic based on data from 2016 to early 2020, but used seasonal auto-regressive integrated moving average models to produce the synthetic counterfactual for the period after 20 January (the first confirmed case of COVID-19 in the US). There was no change in crime levels between the observed and predicted values before early March, when social distancing measures (like closing schools and then stay at home orders) were introduced. There was some evidence of an impact on property crime, including burglary and theft from vehicles; however, Ashby (2020) observed significant variation between the cities, with no two cities exhibiting the same trends in crime.

In Sweden, where containment measures have been less stringent than elsewhere, Gerell et al. (2020) compared the weekly crime numbers in 2020 with the median from three previous years, and observed declines in residential burglary, commercial burglary, and pickpocketing. The decline in pickpocketing offences was particularly noteworthy.

Overall, the strongest evidence in terms of the short-term impact of COVID-19 appears to be for property crimes in locations directly impacted by containment measures - particularly retail settings - and those which are likely to be the result of the incidental contact between motivated offenders and suitable targets/victims in public places. There was mixed evidence with respect to burglary, despite the significant increase in guardianship in the home. Further, the variation between cities suggests different effects, which is likely a consequence of the different containment measures (and timing of those measures) and different patterns of crime that exists within those settings. Importantly, each of these studies has focused on the initial weeks following the introduction of containment measures, particularly more stringent measures, meaning that it might still be too early to have detected any meaningful impact on crime.

\section{Methodology}

\subsection{Data}

These data are drawn from the Queensland Government's Open Data Portal (ODP; Queensland Government, 2020). The ODP reports state-wide monthly offence rates per 100,000 of the Queensland population. The most recent addition to these data were for the month of March 2020-the same month in which the state of Queensland introduced significant social distancing regulations. For this study, we use the offence rates for five types of property crime: property damage, shop theft, other theft, burglary, fraud (including the subcategory of credit-card fraud) and motor-vehicle theft.

\subsection{Analytical approach}

For each of the five violent offence categories, we operationalise an Auto Regressive Integrated Moving Average (ARIMA) model on the monthly offence rate between February 2014 and February 2020. ARIMA models are a specific type of time series forecasting technique which capitalise on several key time-series parameters-the series trend and seasonality, its lagged auto correlations and its lagged partial auto-correlations (correlations between residual errors). Put simply, past values of each time series are used to identify predictable patterns. These patterns are then used to specify a statistical model from which forecasts can be computed. Like all models, the relative accuracy of any forecast depends on the strength of the relationship between past and future values. 
In each series, we exclude from the analysis the observed value for March 2020 since this is the month when social distancing restrictions were first introduced in Queensland. Each series also requires a unique ARIMA specification, depending on the presence (or absence) of seasonality and the unique nature of the series trend, auto-correlation and partial auto-correlation. Procedurally, we begin each model with a statistical assessment of the presence of a unit-root (non-stationarity). A unit-root is a stochastic trend which represents a systematic pattern that is unpredictable. Any time-series which evidence a unit-root must be first de-seasonalised or first-differenced before ARIMA modelling can be performed. To explore stationarity, the Augmented Dickey-Fuller (ADF) test is used. The null-hypothesis of the ADF test is that the raw series is non-stationary (ie. includes a unit-root). Failure to reject the null-hypothesis at $\mathrm{p}<0.05$ indicates the presence of a unit-root and necessitates its removal.

Where there is some evidence of non-stationarity, the unit root is removed by seasonal and trend differencing. The raw series is used for subsequent ARMA modelling if the ADF test indicates stationarity. If not, the seasonality-differenced and firstdifferenced series is used, either separately or combined, depending on which produces the superior fit to the data. The base seasonality adjustment is SARIMA $(0,1,0,12)$, where the purpose of seasonality differencing is to paramatise the additive seasonal patterns in the raw data. Second, and where needed, non-stationarity in the trend is removed using first-differencing. The base adjustment for non-stationarity in the trend is $\operatorname{ARMA}(0,1,0)$. Therefore, a series that requires both trend and seasonality differencing is known as $\operatorname{ARIMA}(0,1,0) \operatorname{SARIMA}(0,1,0,12)$.

Subsequent to any adjustments, each offence series is then explored using Auto-Correlation (AC) and Partial Auto-Correlation (PAC) plots. These plots help to determine the most likely specification of the seasonal and trend-level Moving Average (MA) and Auto Regressive (AR) parameters. From here the modelling is iterative and each specification seeks to identify the unique AR and MA specifications which best fit the observed data. As with all modelling, there is a trade-off between parsimony and best fit, so we use the Aikake Information Criteria (AIC) and the Baysian Information Criteria (BIC) to guide final model selection.

At the conclusion of the modelling procedure for each property offence, we use the final ARIMA specification to forecast both point estimates and their mean square errors (MSE). The MSE is used to calculate $95 \%$ confidence intervals up to and including September 2020. We then compare the observed offence rate for March 2020 to the forecasted point estimate for the same month. We also consider its position within the confidence interval of the forecast and we only conclude that the offence rate has changed under COVID-19 conditions if the observed value (for March 2020) falls outside the upper or lower bounds of the $95 \%$ confidence interval.

\section{Results}

\subsection{Property Damage}

Between February 2014 and February 2020, the rate of common assault in Queensland has fluctuated between 49.8 and 69.1 recorded offences per 100,000 of the population. The observed rate in March 2020 was 62.2 per 100,000, up on the previous month $(58.8$ per 100,000$)$ and slightly lower than the same time in the previous year $(62.6$ per 100,000). Comparative tests (Table 1) confirm the need for trend-level first-differencing and inspection of the AC and PAC plots indicate significant autocorrelations at lags 1 and 12 .

The specification that best fit these data was $\operatorname{ARIMA}(0,1,1 \& 12)$ SARIMA $(1,0,0,12)$ (AIC=376.13). The modelled parameters are provided in Table 2 and a plot of the observed and model-derived estimates is provided in Figure 1. It shows that while the model captures the overall trend and some of the peaks and troughs, there is still some degree of variability (or 'noise') in the series that is not easily determined by earlier patterns. This unpredictability necessarily makes forecasts less reliable and manifests as wide confidence intervals as seen in Figure 4.

As for March 2020 (see Figure 5), the observed rate of property damage $(62.2$ per 100,000) was lower than the forecasted rate $(64.2$ per 100,000) but clearly falls well within the $95 \%$ confidence interval for that time period (between $58.5-69.9$ per 100,000). Therefore, we cannot conclude that the rate of common assault changed beyond what might have been expected given the historical trends in that offence type.

[Figure 4 about here.]

[Figure 5 about here.]

\subsection{Shop Stealing}

Since February 2014, the rate of shop sealing in Queensland has fluctuated between 27.2 and 56.0 offences per 100,000 of the population. In March 2020, the observed rate was 46.6 per 100,000. This was lower than previous month (49.9 per 100,000) and slightly lower than at the same time in the previous year $(47.2$ per 100,000). Comparative model tests (Table 3 ) indicate the 
Table 1: ARIMA Model Selection for PROPERTY DAMAGE (Feb 2014 - Feb 2020)

\begin{tabular}{|c|c|c|c|c|c|c|c|}
\hline Model & Description & Specification & Obs & 11(model) & df & $\mathrm{AIC}$ & $\mathrm{BIC}$ \\
\hline 1 & Constant only & ARIMA $(0,0,0)$ SARIMA $(0,1,0,12)$ & 73 & -210.009 & 2 & 424.0179 & 428.5989 \\
\hline 2 & Seasonal differencing & $\operatorname{ARIMA}(0,0,0) \operatorname{SARIMA}(0,1,0,12)$ & 73 & -229.967 & 1 & 461.9345 & 464.2249 \\
\hline 3 & Trend differencing & $\operatorname{ARIMA}(0,1,0) \operatorname{SARIMA}(0,0,0,12)$ & 73 & -208.579 & 1 & 419.158 & 421.4484 \\
\hline 4 & Seasonal \& Trend differencing & $\operatorname{ARIMA}(0,1,0) \operatorname{SARIMA}(0,1,0,12)$ & 73 & -210.212 & 1 & 422.4235 & 424.714 \\
\hline 5 & Model 3 with Seasonal MA1 & $\operatorname{ARIMA}(0,1,0) \operatorname{SARIMA}(0,0,1,12)$ & 73 & nc & nc & nc & nc \\
\hline 6 & Model 3 with Seasonal AR1 & $\operatorname{ARIMA}(0,1,0)$ SARIMA $(1,0,0,12)$ & 73 & -191.534 & 2 & 387.0669 & 391.6479 \\
\hline 7 & Model 3 with Seasonal AR1 \& MA1 & $\operatorname{ARIMA}(0,1,0) \operatorname{SARIMA}(1,0,1,12)$ & 73 & nc & nc & nc & nc \\
\hline 8 & Model 6 with Trend AR1 & $\operatorname{ARIMA}(1,1,0) \operatorname{SARIMA}(1,0,0,12)$ & 73 & -186.596 & 3 & 379.191 & 386.0623 \\
\hline 9 & Model 6 with Trend MA1 & $\operatorname{ARIMA}(0,1,1)$ SARIMA $(1,0,0,12)$ & 73 & -185.065 & 3 & 376.1306 & 383.002 \\
\hline 10 & Model 6 with Trend AR2 \& MA2 & $\operatorname{ARIMA}(1,1,1)$ SARIMA $(1,0,0,12)$ & 73 & -185.054 & 4 & 378.1082 & 387.27 \\
\hline 11 & Model 6 with Trend MA2 & $\operatorname{ARIMA}(0,1,2) \operatorname{SARIMA}(1,0,0,12)$ & 73 & -185.051 & 4 & 378.101 & 387.2628 \\
\hline
\end{tabular}

Note: The ML likelihood estimation of Model 5 and 7 did not converge

Note: Final model indicated in bold. Source: Queensland Offence rates, Open Data Portal

Table 2: ARIMA Model parameters for PROPERTY DAMAGE (Feb 2014 - Feb 2020)

\begin{tabular}{lccc}
\hline \multicolumn{1}{l}{ Trend } & coeff & std. err. & $\mathrm{p}$ \\
MA1 & -0.47 & 0.11 & 0.00 \\
Seasonal & & & \\
AR1 & 0.69 & 0.07 & 0.00 \\
/sigma & 2.88 & 0.25 & 0.00 \\
\hline
\end{tabular}

Model: $\operatorname{ARIMA}(0,1,1)$ SARIMA(1,0,0,12)

Source: Queensland Offence rates, Open Data Portal

need for both trend and seasonality differencing, while the AC and PAC plots indicate the need for seasonal AR and trend-level MA parameters.

The best fitting model was specified as ARIMA(0,1,1) SARIMA(0,1,1,12) (AIC=335.43) and the final modelled parameters are provided in Table 4. A plot of the observed and modelled data is provided in Figure 6. Overall the model captures both the series trend and its seasonal peaks and troughs; however there is still some period-specific variability that was not easily predicted. Overall, the observed rate of shop stealing in March 2020 (46.6 per 100,000) was lower than forecast from the historical series $(54.5$ per 100,000) and was lower, in fact, than the lower bound of the $95 \%$ confidence interval (50.2 - 58.7 per 100,000) (Figure 7). We conclude, therefore, that the rate of shop stealing was lower than statistically expected had social conditions remained unchanged in Queensland.

Table 3: ARIMA Model Selection for SHOP STEALING (Feb 2014 - Feb 2020)

\begin{tabular}{|c|c|c|c|c|c|c|c|}
\hline Model & Description & Specification & Obs & 1l(model) & df & AIC & $\mathrm{BIC}$ \\
\hline 1 & Constant only & ARIMA $(0,0,0)$ SARIMA $(0,1,0,12)$ & 73 & -243.10 & 2 & 490.21 & 494.79 \\
\hline 2 & Seasonal differencing & $\operatorname{ARIMA}(0,0,0) \operatorname{SARIMA}(0,1,0,12)$ & 73 & -219.50 & 1 & 441.00 & 443.29 \\
\hline 3 & Trend differencing & $\operatorname{ARIMA}(0,1,0) \operatorname{SARIMA}(0,0,0,12)$ & 73 & -187.96 & 1 & 377.92 & 380.21 \\
\hline 4 & Seasonal \& Trend differencing & $\operatorname{ARIMA}(0,1,0)$ SARIMA $(0,1,0,12)$ & 73 & -178.65 & 1 & 359.31 & 361.60 \\
\hline 5 & Model 4 with Seasonal MA1 & $\operatorname{ARIMA}(0,1,0) \operatorname{SARIMA}(0,1,1,12)$ & 73 & -171.17 & 2 & 346.33 & 350.91 \\
\hline 6 & Model 4 with Seasonal AR1 & $\operatorname{ARIMA}(0,1,0) \operatorname{SARIMA}(1,1,0,12)$ & 73 & -172.52 & 2 & 349.04 & 353.62 \\
\hline 7 & Model 4 with Seasonal AR1 \& MA1 & ARIMA( $(0,1,0)$ SARIMA $(1,1,1,12)$ & 73 & -171.14 & 3 & 348.28 & 355.15 \\
\hline 8 & Model 5 with Trend MA1 & $\operatorname{ARIMA}(0,1,1)$ SARIMA $(0,1,1,12)$ & 73 & -164.71 & 3 & 335.43 & 342.30 \\
\hline 9 & Model 5 with Trend AR1 & $\operatorname{ARIMA}(1,1,0) \operatorname{SARIMA}(0,1,1,12)$ & 73 & -167.59 & 3 & 341.18 & 348.05 \\
\hline 10 & Model 5 with Trend AR2 \& MA2 & $\operatorname{ARIMA}(1,1,1) \operatorname{SARIMA}(0,1,1,12)$ & 73 & -164.06 & 4 & 336.13 & 345.29 \\
\hline
\end{tabular}

Note: Final model indicated in bold. Source: Queensland Offence rates, Open Data Portal

[Figure 6 about here.]

[Figure 7 about here.] 
A PREPRINT - MAY 2020

Table 4: ARIMA Model parameters for SHOP STEALING (Feb 2014 - Feb 2020)

\begin{tabular}{lccc}
\hline \multicolumn{1}{l}{ Trend } & coeff & std. err. & $\mathrm{p}$ \\
MA1 & -0.53 & 0.10 & 0.00 \\
Seasonal & & & \\
MA1 & -0.68 & 0.16 & 0.01 \\
/sigma & 2.19 & 0.25 & 0.00 \\
\hline Model: ARIMA $(0,1,1)$ SARIMA $(0,1,1,12)$ & &
\end{tabular}

Source: Queensland Offence rates, Open Data Portal

\subsection{Other theft}

Since February 2014 the rate of other theft in Queensland has fluctuated between 156.7 and 267.8 offences per 100,000 of the population. In March 2020, the observed rate was 234.2 per 100,000. This was lower than previous month (240.1 per 100,000) but higher than at the same time in the previous year (217.0 per 100,000). Comparative model tests (Table 4) indicate the need for both trend and seasonality differencing, while the AC and PAC plots indicate the need for seasonal AR and trend-level MA parameters.

The best fitting model was specified as $\operatorname{ARIMA}(0,1,1) \operatorname{SARIMA}(0,1,1,12)(\mathrm{AIC}=519.30)$ and the final modelled parameters are provided in Table 5. A plot of the observed and modelled data is provided in Figure 7. Overall, the model captures with reasonable precision the series trend and its seasonal peaks and troughs. The observed rate of other theft in March 2020 (234.2 per 100,000) was lower than forecast from the historical series $(255.8$ per 100,000) and was lower, in fact, than the lower bound of the $95 \%$ confidence interval (240.3 - 271.3 per 100,000) (Figure 8). We conclude, therefore, that the rate of other theft was statistically lower than would have been expected had social conditions remained unchanged in Queensland.

Table 5: ARIMA Model Selection for OTHER THEFT (Feb 2014 - Feb 2020)

\begin{tabular}{|c|c|c|c|c|c|c|c|}
\hline Model & Description & Specification & Obs & 11(model) & df & AIC & $\mathrm{BIC}$ \\
\hline 1 & Constant only & ARIMA $(0,0,0)$ SARIMA $(0,1,0,12)$ & 73 & -335.92 & 2 & 675.85 & 680.43 \\
\hline 2 & Seasonal differencing & $\operatorname{ARIMA}(0,0,0) \operatorname{SARIMA}(0,1,0,12)$ & 73 & -308.60 & 1 & 619.21 & 621.50 \\
\hline 3 & Trend differencing & $\operatorname{ARIMA}(0,1,0) \operatorname{SARIMA}(0,0,0,12)$ & 73 & -287.51 & 1 & 577.02 & 579.31 \\
\hline 4 & Seasonal \& Trend differencing & $\operatorname{ARIMA}(0,1,0) \operatorname{SARIMA}(0,1,0,12)$ & 73 & -262.49 & 1 & 526.98 & 529.27 \\
\hline 5 & Model 4 with Seasonal MA1 & $\operatorname{ARIMA}(0,1,0) \operatorname{SARIMA}(0,1,1,12)$ & 73 & -259.50 & 2 & 523.01 & 527.59 \\
\hline 6 & Model 4 with Seasonal AR1 & $\operatorname{ARIMA}(0,1,0) \operatorname{SARIMA}(1,1,0,12)$ & 73 & -260.00 & 2 & 523.99 & 528.57 \\
\hline 7 & Model 4 with Seasonal AR1 \& MA1 & ARIMA(0,1,0) SARIMA $(1,1,1,12)$ & 73 & -258.31 & 3 & 522.61 & 529.49 \\
\hline 8 & Model 5 with Trend MA1 & ARIMA(0,1,1) SARIMA(0,1,1,12) & 73 & -256.65 & 3 & 519.30 & 526.17 \\
\hline 9 & Model 5 with Trend AR1 & $\operatorname{ARIMA}(1,1,0) \operatorname{SARIMA}(0,1,1,12)$ & 73 & -257.76 & 3 & 521.51 & 528.38 \\
\hline 10 & Model 5 with Trend AR1 \& MA1 & $\operatorname{ARIMA}(1,1,1) \operatorname{SARIMA}(0,1,1,12)$ & 73 & -256.13 & 4 & 520.26 & 529.43 \\
\hline
\end{tabular}

Note: Final model indicated in bold. Source: Queensland Offence rates, Open Data Portal

Table 6: ARIMA Model parameters for OTHER THEFT (Feb 2014 - Feb 2020)

\begin{tabular}{lccc}
\hline \multicolumn{1}{c}{ coeff } & std. err. & $\mathrm{p}$ \\
MA1 & -0.34 & 0.12 & 0.00 \\
Seasonal & & & \\
MA1 & -0.42 & 0.14 & 0.00 \\
/sigma & 8.00 & 0.87 & 0.00 \\
\hline
\end{tabular}

Model: $\operatorname{ARIMA}(0,1,1) \operatorname{SARIMA}(0,1,1,12)$

Source: Queensland offence rates, Open Data Portal

[Figure 8 about here.]

[Figure 9 about here.] 


\subsection{Burglary}

Since February 2014, rates of burglary (unlawful entry with intent) in Queensland have ranged between 49.6 and 88.4 per 100,000 of the population. The observed result for March 2020 was 90.5 per 100,000. This was higher than in the previous month $(88.4$ per 100,000) and higher than at the same time in the previous year $(68.0$ per 100,000$)$. Comparative model tests (Table 5) indicate the need for trend differencing, which AC and PAC plots indicated the need for seasonal AR and trend-level MA parameters.

The final and best fitting model was specified as ARIMA(0,1,1) SARIMA(1,0,0,12) (AIC=428.42). The model parameters are presented in Table 6 and their graphical plot is provided in Figure 8. As for the observed rate of burglary in March 2020, the rate $(90.5$ per 100,000$)$ was only slightly higher than the forecast $(88.0$ per 100,000) (Figure 9) and did not exceed the 95\% confidence intervals of the estimate (79.6 to 96.4 per 100,000). It should be noted, however, that the observed data for the months of January $(83.7$ per 100,000$)$ and February $(88.4$ per 100,000$)$ were unusually high and did, in fact, exceed the confidence intervals of the forecasts for those two months. To be sure, an inspection of the observed burglary data in Figure 8 shows that rates had increased quite dramatically from January 2020, an increase that was somewhat unusual given the history of the series. This has a two important implications. First, it appears that any observed increase in recorded rates of burglary began well before any COVID-19 related restrictions were introduced in Queensland. Second, it may then be difficult to disentangle the independent contribution of COVID-19 in later months (April and May because of what appears to be a structural break in the series starting prior to the restrictions. If burglary rates increase in April, it may be difficult to discern whether this is just a continuation of the pre-COVID-19 trend. Conversely, if burglary rates fall in future months it may be difficult to conclude anything other than that the series is returning to its structural long-term trend.

Table 7: ARIMA Model Selection for BURGLARY (Feb 2014 - Feb 2020)

\begin{tabular}{llllllll}
\hline Model & Description & Specification & Obs & ll(model) & df & AIC & BIC \\
\hline 1 & Constant only & ARIMA(0,0,0) SARIMA(0,1,0,12) & 73 & -248.04 & 2 & 500.09 & 504.67 \\
2 & Seasonal differencing & ARIMA(0,0,0) SARIMA(0,1,0,12) & 73 & -258.92 & 1 & 519.85 & 522.14 \\
3 & Trend differencing & ARIMA(0,1,0) SARIMA(0,0,0,12) & 73 & -218.53 & 1 & 439.05 & 441.35 \\
4 & Seasonal \& Trend differencing & ARIMA(0,1,0) SARIMA(0,1,0,12) & 73 & -226.59 & 1 & 455.17 & 457.47 \\
5 & Model 4 with Seasonal MA1 & ARIMA(0,1,0) SARIMA(0,1,1,12) & 73 & -213.12 & 2 & 430.25 & 434.83 \\
6 & Model 4 with Seasonal AR1 & ARIMA(0,1,0) SARIMA(1,1,0,12) & 73 & -212.96 & 2 & 429.91 & 434.49 \\
7 & Model 4 with Seasonal AR1 \& MA1 & ARIMA(0,1,0) SARIMA(1,1,1,12) & 73 & -212.93 & 3 & 431.86 & 438.73 \\
8 & Model 6 with Trend AR1 & ARIMA(0,1,1) SARIMA(1,1,0,12) & 73 & -211.68 & 3 & 429.36 & 436.23 \\
$\mathbf{9}$ & Model 6 with Trend MA1 & ARIMA(1,1,0) SARIMA(1,1,0,12) & $\mathbf{7 3}$ & $\mathbf{- 2 1 1 . 2 1}$ & $\mathbf{3}$ & $\mathbf{4 2 8 . 4 2}$ & $\mathbf{4 3 5 . 2 9}$ \\
10 & Model 6 with Trend AR1 \& MA1 & ARIMA(1,1,1) SARIMA(1,1,0,12) & 73 & -210.67 & 4 & 429.34 & 438.51 \\
\hline
\end{tabular}

Note: Final model indicated in bold. Source: Queensland Offence rates, Open Data Portal

Table 8: ARIMA Model parameters for BURGLARY (Feb 2014 - Feb 2020)

\begin{tabular}{llll}
\hline & coeff & std. err. & $\mathrm{p}$ \\
\hline $\begin{array}{l}\text { Trend } \\
\text { MA1 }\end{array}$ & -0.27 & 0.14 & 0.05 \\
$\begin{array}{l}\text { Seasonal } \\
\text { AR1 }\end{array}$ & 0.42 & 0.10 & 0.00 \\
/sigma & 1.57 & 0.13 & 0.00 \\
\hline $\begin{array}{l}\text { Model: ARIMA(0,1,1) SARIMA(1,1,0,12) } \\
\text { Source: Queensland Offence rates, Open Data Portal }\end{array}$ &
\end{tabular}

[Figure 10 about here.]

[Figure 11 about here.]

\subsection{Motor Vehicle Theft}

Since February 2014, motor vehicle theft (unlawful use) has occurred in Queensland at a rate of between 14.2 and 32.1 per 100,000 of the population. The observed motor vehicle theft rate in March 2020 was 33.8 per 100,000 which was higher than in the previous month (32.1 per 100,000) and higher than it was in March of the previous year $(26.6$ per 100,000). It is notable that 
both February and March 20202, were the two highest monthly rates in this time period. Comparative model analysis (Table 7) indicated the need for both seasonal and trend differencing. AC and PAC plots suggested significant auto-correlations and partial auto-correlations at lag 1.

The best fitting model-ARIMA(0,1,1) SARIMA(1,1,0,12)-required an MA parameter at lag 1 for the trend and an AR parameter at lag 1 in the seasonal pattern $(\mathrm{AIC}=280.33)$. The final model specifications can be found in Table 8 and the modelled results are graphically presented in Figure 10. Overall, the model fit the data well. The observed motor vehicle theft rate in March 2020 (33.8 per 100,000) was lower than forecast by the model (35.4 per 100,000) (Figure 11) and did not exceed the confidence intervals of the estimate (32.4 to 38.5 per 100,000). Much like burglary, the rate of motor vehicle theft appears to have increased in January and February before the COVID-19 restrictions came into effect.

Table 9: ARIMA Model Selection for MOTOR VEHICLE THEFT (Feb 2014 - Feb 2020)

\begin{tabular}{|c|c|c|c|c|c|c|c|}
\hline Model & Description & Specification & Obs & ll(model) & $\mathrm{df}$ & AIC & BIC \\
\hline 1 & Constant only & ARIMA $(0,0,0)$ SARIMA $(0,1,0,12)$ & 73 & -209.56 & 2 & 423.13 & 427.71 \\
\hline 2 & Seasonal differencing & $\operatorname{ARIMA}(0,0,0)$ SARIMA $(0,1,0,12)$ & 73 & -191.43 & 1 & 384.87 & 387.16 \\
\hline 3 & Trend differencing & $\operatorname{ARIMA}(0,1,0) \operatorname{SARIMA}(0,0,0,12)$ & 73 & -150.04 & 1 & 302.07 & 304.36 \\
\hline 4 & Seasonal \& Trend differencing & $\operatorname{ARIMA}(0,1,0) \operatorname{SARIMA}(0,1,0,12)$ & 73 & -141.01 & 1 & 284.03 & 286.32 \\
\hline 5 & Model 4 with Seasonal MA1 & $\operatorname{ARIMA}(0,1,0) \operatorname{SARIMA}(0,1,1,12)$ & 73 & -138.91 & 2 & 281.82 & 286.40 \\
\hline 6 & Model 4 with Seasonal AR1 & $\operatorname{ARIMA}(0,1,0) \operatorname{SARIMA}(1,1,0,12)$ & 73 & -138.67 & 2 & 281.34 & 285.92 \\
\hline 7 & Model 4 with Seasonal AR1 \& MA1 & $\operatorname{ARIMA}(0,1,0)$ SARIMA $(1,1,1,12)$ & 73 & -138.46 & 3 & 282.92 & 289.79 \\
\hline 8 & Model 6 with Trend AR1 & $\operatorname{ARIMA}(0,1,1)$ SARIMA $(1,1,0,12)$ & 73 & -137.67 & 3 & 281.34 & 288.21 \\
\hline 9 & Model 6 with Trend MA1 & $\operatorname{ARIMA}(1,1,0)$ SARIMA $(1,1,0,12)$ & 73 & -137.17 & 3 & 280.33 & 287.20 \\
\hline 10 & Model 6 with Trend AR1 \& MA1 & $\operatorname{ARIMA}(1,1,1) \operatorname{SARIMA}(1,1,0,12)$ & 73 & -136.81 & 4 & 281.62 & 290.78 \\
\hline
\end{tabular}

Note: Final model indicated in bold. Source: Queensland Offence rates, Open Data Portal

Table 10: ARIMA Model parameters for MOTOR VEHICLE THEFT (Feb 2014 - Feb 2020)

\begin{tabular}{llll}
\hline & coeff & std. err. & $\mathrm{p}$ \\
\hline $\begin{array}{l}\text { Trend } \\
\text { MA1 }\end{array}$ & -0.26 & 0.13 & 0.05 \\
Seasonal & & \\
AR1 & -0.28 & 0.13 & 0.00 \\
/sigma & 1.57 & 0.13 & 0.00 \\
\hline $\begin{array}{l}\text { Model: ARIMA(0,1,1) SARIMA(1,1,0,12) } \\
\text { Source: Queensland Offence rates, Open Data Portal }\end{array}$ &
\end{tabular}

[Figure 12 about here.]

[Figure 13 about here.]

\subsection{Fraud}

Rates of fraud in Queensland fluctuate considerably, making the recorded series highly volatile and difficult to model using only the lagged values of same series (Figure 12). For example, rates of fraud since February 2014 have fluctuated from as low as 29.3 offences per 100,000 to as high as 78.1 per 100,000. The observed rate of fraud in March 2020 was 36.9 per 100,000 and this was lower than recorded in the previous month (45.4 per 100,000) and lower than recorded in March of the previous year (44.6 per 100,000). There has been a modest upward trend, but the volatility represents a high degree of 'noise' which complicated dynamic forecasting. Comparative model analysis (Table 7) indicated the need for both seasonal and trend differencing. AC and PAC plots suggested significant auto-correlations and partial auto-correlations at lag 1.

The best fitting model-ARIMA(0,1,1) SARIMA(0,0,0,12)-required only an MA parameter at lag 1 for the trend. The results of the model are graphically presented in Figure 10 and who just exactly how difficult the volatility has been to predict at the univariate level and this unpredictability has translated in wide confidence intervals that make it difficult to assess any periodby-period changes. The observed fraud rate in March 2020 (36.9 per 100,000) was lower than forecast by the model (49.3 per $100,000)$ (Figure 13) and was approaching the confidence interval but did not fall outside the range of plausible values (31.7 to 66.9 per 100,000$)$. 
A PREPRINT - MAY 2020

Table 11: ARIMA Model Selection for FRAUD (Feb 2014 - Feb 2020)

\begin{tabular}{|c|c|c|c|c|c|c|c|}
\hline Model & Description & Specification & Obs & ll(model) & $\mathrm{df}$ & AIC & BIC \\
\hline 1 & Constant only & ARIMA $(0,0,0)$ SARIMA $(0,1,0,12)$ & 73 & -266.39 & 2.0 & 536.79 & 541.37 \\
\hline 2 & Seasonal differencing & $\operatorname{ARIMA}(0,0,0) \operatorname{SARIMA}(0,1,0,12)$ & 73 & -285.03 & 1.0 & 572.07 & 574.36 \\
\hline 3 & Trend differencing & $\operatorname{ARIMA}(0,1,0)$ SARIMA $(0,0,0,12)$ & 73 & -284.69 & 1.0 & 571.38 & 573.67 \\
\hline 4 & Seasonal \& Trend differencing & $\operatorname{ARIMA}(0,1,0) \operatorname{SARIMA}(0,1,0,12)$ & 73 & -301.81 & 1.0 & 605.61 & 607.90 \\
\hline 5 & Model 3 with Seasonal MA1 & $\operatorname{ARIMA}(0,1,0) \operatorname{SARIMA}(0,0,1,12)$ & 73 & -283.98 & 2.0 & 571.95 & 576.53 \\
\hline 6 & Model 3 with Seasonal AR1 & $\operatorname{ARIMA}(0,1,0) \operatorname{SARIMA}(1,0,0,12)$ & 73 & -283.79 & 2.0 & 571.58 & 576.16 \\
\hline 7 & Model 3 with Seasonal AR1 \& MA1 & $\operatorname{ARIMA}(0,1,0) \operatorname{SARIMA}(1,0,1,12)$ & 73 & -282.70 & 3.0 & 571.39 & 578.26 \\
\hline 8 & Model 3 with Trend AR1 & $\operatorname{ARIMA}(1,1,0) \operatorname{SARIMA}(0,0,0,12)$ & 73 & -277.83 & 2.0 & 559.66 & 564.25 \\
\hline 9 & Model 3 with Trend MA1 & $\operatorname{ARIMA}(0,1,1)$ SARIMA(0,0,0,12) & 73 & -264.58 & 2.0 & 533.16 & 537.74 \\
\hline 10 & Model 3 with Trend AR1 \& MA1 & $\operatorname{ARIMA}(0,1,1) \operatorname{SARIMA}(0,0,0,12)$ & 73 & -264.57 & 3.0 & 535.13 & 542.01 \\
\hline
\end{tabular}

Note: Final model indicated in bold. Source: Queensland Offence rates, Open Data Portal

Table 12: ARIMA Model parameters for MOTOR VEHICLE THEFT (Feb 2014 - Feb 2020)

\begin{tabular}{llll}
\hline \multicolumn{1}{c}{ coeff } & std. err. & $\mathrm{p}$ \\
Trend & -0.26 & 0.13 & 0.05 \\
Seasonal & & \\
AR1 & -0.28 & 0.13 & 0.03 \\
/sigma & 1.57 & 0.13 & 0.00 \\
\hline $\begin{array}{l}\text { Model: ARIMA(0,1,1) SARIMA(1,1,0,12) } \\
\text { Source: Queensland Offence rates, Open Data Portal }\end{array}$ &
\end{tabular}

[Figure 14 about here.]

[Figure 15 about here.]

The fraud data have proven difficult to model and forecast given the high volatility in the series. Nevertheless, the observed rate in March edged near the predicted confidence interval, so much so that it raises questions about whether hidden in the data are different trends for different types of fraud. Given our conclusion earlier about the significant fall in shop-theft, we might imagine that retail-related fraud have responded differently to the types of fraudulent behaviour. To offer some insight into this, we separate from the fraud estimates a distinct measure for the monthly rate of credit-card fraud. Being more likely to occur in retail locations and outlets, we might expect the credit-card fraud to have followed in the same direction as shop stealing for example.

Table 9 provides the comparative ARIMA model outcomes for rates of credit-card fraud while Figure 14 plots the long-term series between February 2014 and February 2020. Table 10 presents the final model parameters and Figure 15 plots the shortterm forecasts and observed rates. The model of best fit was specified as ARIMA(1,1,1), requiring trend differencing together with an AR and MA parameter at lag 1. Using this model, we note that the observed rate of credit card fraud in March 2020 (17.8 per 100,000) was significantly lower than the model predicted $(25.0$ per 100,00$)$ and fell beyond the lower-limit of the $95 \%$ confidence interval (18.1 to 32.0 per 100,00$)$.

[Figure 16 about here.]

[Figure 17 about here.]

\section{Discussion}

This study offers one of the first Australian analyses of the extent to which property crime has changed during the early stages of the COVID-19 pandemic. Specifically, we use an iterative univariate ARIMA framework to model the six-year trend in the state-wide rates of six property crime types (property damage, shop stealing, other theft, burglary, motor vehicle theft and fraud) in Queensland, Australia. We capitalise on the period-by-period and seasonal patterns in each series to generate dynamic forecasts (and their 95\% confidence intervals). We then compared these forecasts with the observed rates for March 2020 . We conclude that there was a statistically significant fall in rates of shop stealing, other theft, and credit card fraud as a specific 
A PREPRINT - MAY 2020

Table 13: ARIMA Model Selection for CREDIT CARD FRAUD (Feb 2014 - Feb 2020)

\begin{tabular}{llllllll}
\hline Model & Description & Specification & Obs & ll(model) & df & AIC & BIC \\
\hline 1 & Constant only & ARIMA(0,0,0) SARIMA(0,1,0,12) & 73 & -220.44 & 2 & 444.89 & 449.47 \\
2 & Seasonal differencing & ARIMA(0,0,0) SARIMA(0,1,0,12) & 73 & -228.89 & 1 & 459.77 & 462.06 \\
3 & Trend differencing & ARIMA(0,1,0) SARIMA(0,0,0,12) & 73 & -205.90 & 1 & 413.81 & 416.10 \\
4 & Seasonal \& Trend differencing & ARIMA(0,1,0) SARIMA $(0,1,0,12)$ & 73 & -234.04 & 1 & 470.08 & 472.37 \\
5 & Model 3 with Seasonal MA1 & ARIMA(0,1,0) SARIMA(0,0,1,12) & 73 & -205.65 & 2 & 415.30 & 419.88 \\
6 & Model 3 with Seasonal AR1 & ARIMA(0,1,0) SARIMA $(1,0,0,12)$ & 73 & -205.63 & 2 & 415.25 & 419.83 \\
7 & Model 3 with Seasonal AR1 \& MA1 & ARIMA(0,1,0) SARIMA $(1,0,1,12)$ & 73 & -205.62 & 3 & 417.24 & 424.11 \\
8 & Model 3 with Trend AR1 & ARIMA(1,1,0) SARIMA(0,0,0,12) & 73 & -203.95 & 2 & 411.89 & 416.48 \\
9 & Model 3 with Trend MA1 & ARIMA(0,1,1) SARIMA(0,0,0,12) & 73 & -199.11 & 2 & 402.22 & 406.81 \\
$\mathbf{1 0}$ & Model 3 with Trend AR1 \& MA1 & ARIMA(1,1,1) SARIMA(0,0,0,12) & $\mathbf{7 3}$ & $\mathbf{- 1 9 6 . 1 2}$ & $\mathbf{3}$ & $\mathbf{3 9 8 . 2 3}$ & $\mathbf{4 0 5 . 1 1}$ \\
\hline
\end{tabular}

Note: Final model indicated in bold. Source: Queensland Offence rates, Open Data Portal

Table 14: ARIMA Model parameters for CREDIT CARD FRAUD (Feb 2014 - Feb 2020)

\begin{tabular}{llll}
\hline & coeff & std. err. & $\mathrm{p}$ \\
\hline Trend & 0.32 & 0.19 & 0.09 \\
AR1 & -1.17 & 0.17 & 0.00 \\
MA1 & 3.02 & 0.55 & 0.00 \\
/sigma & &
\end{tabular}

Source: Queensland Offence rates, Open Data Portal

sub-category of fraud. Other property crime types, such as property damage, burglary and motor vehicle theft were unchanged. These findings are generally consistent with the emerging international evidence.

We caution, however, in treating these early data as a definitive test of the crime-response to COVID-19. In our view, it is simply too early to make that judgement. To be sure, March 2020 was the month in which the most significant social distancing rules were first introduced in Queensland. However, their introduction occurred in the second half of the month and may not have translated (at least not yet) into a measurable change in rates of burglary, motor vehicle theft and property damage. April crime data, soon to be released in Queensland, will likely provide a more robust assessment for an entire month when social distancing was in effect. The dynamic forecasts presented in this study, and their confidence intervals, will be a useful tool in making that assessment.

Notwithstanding this caution, we note that the three property crime types signalling an early change are theft or fraud-related offences which are more likely to occur in retail settings or in high use business districts which normally have significant pedestrian traffic. Shop stealing and credit card fraud are both crime types which are likely to be significantly and immediately affected by the state-wide social distancing rules which mandated the closure of some retail precincts, limited trading hours of major stores, and which saw an increase in the presence of physical security personnel to monitor social distancing and intervene to prevent panic buying. Each of these actions, made in the interests of public health and safety, nevertheless are likely to have a significant impact on retail-related crime. Specifically, we believe that the opportunities for shop stealing were limited (by restrictions on retail opening hours), target hardened (by the increased presence of surveillance and security), or removed altogether (by retail store closure), meaning that fewer motivated offenders could take advantage of (or encounter) opportunities to steal. This is supported, in part, by Google's mobility trend data, where there was a large but gradual decrease in the use of retail and recreation locations, and an increase in time spent at home, towards the end of the March. It is possible that the impact of these containment measures, particularly in terms of influencing routine activities, will have first had their greatest impact on those crime opportunities directly connected to retail locations that were closed, guarded by security, or limited by restrictions in treading hours.

For the category of 'other theft' we offer a similar explanation in that the convergence of motivated offenders with vulnerable victims was likely to have been significantly impacted by the re-configuring of routine activities connected to key retail and economic activities. This category of other theft captures non-assaultive stealing offences in which the primary victim was not a retail premise. This would include the theft of other personal items and belongings, such as mobile phones, handbags, and wallets, often in business, retail or entertainment districts, or on public transport. In fact, one Australian study showed as much as 60 percent of these stealing offences occurred on public transport, at workplaces or at licensed premises, all of which have been significantly impacted (Burgess Grech, 2011). A further 25 percent of offences occurred in other public spaces. For the same reasons as above, the opportunities for this type of crime are likely to have been significantly reduced as large segments 
of the population opted to stay at home and limit the frequency and length of their visits to public places. However motivated some offenders might have been, it is undoubtable that strong social distancing regulations limited the number of vulnerable victims and thus reduced the number of possible criminal opportunities.

The absence of a COVID-19-related change signal in burglary and motor vehicle theft motor is a notable finding, although we are keen to see what happens in April. In our view, the routine activity and opportunity structures which make possible these more serious forms of theft are not likely to have been as easily or quickly influenced by social distancing in Queensland. Social distancing did not, for example, impact the total stock of vehicles in Queensland, nor would it have prevented vehicles from being parked in places or contexts that make them vulnerable to theft. This might have changed much later in March as more people stayed home from work, but too late to be reflected in these March figures. Similarly, burglary opportunities are not likely to have been affected as rapidly as retail opportunities, and so we eagerly await April data to see whether fewer burglaries occurred under social distancing conditions. It is possible that a reduction in residential burglary is offset, at least in part, by an increase in commercial burglary, but we do not have the data available to make that distinction. However, given what we know about displacement, it is unlikely that this increase would fully offset the fall in residential burglary. Our prediction is that both motor vehicle theft and burglary will decline, simply because broader social distancing regulations kept members of the public at home, acting as natural capable guardians of their own property and vehicles.

We end with a brief reflection on what is to come. Specifically, we have drawn heavily here on routine activity theory to explain these early changes to property crime. In our view, this is the most plausible framework for explaining imminent changes of the kind we have witnessed here. However, we also recognise that other factors may begin to operate and influence crime rates in different ways as the pandemic progresses. Specifically, we have assumed that in such a short period of time the number of motivated offenders will not have increased (or decreased), only that routine activities will have restructured opportunities for offending such that motivated offenders are less likely to encounter suitable targets. This might change if recent employment figures translate into higher rates of unemployment or under-employment in the longer-term, especially among youth and young adult populations, or if the containment measures exert undue stress on the community or extend for so long as to lead to resentment. In any case, how property crime rates respond to this once-in-a-generation global event will provide invaluable foreground for theoretical analysis into the nature of crime among the people who offend.

\section{References}

Agnew, R. (1992). Foundation for a general strain theory of crime and delinquency. Criminology, 30(1), 47-88. https://doi.org/ 10.1111/j.1745-9125.1992.tb01093.x

Ashby, M. (2020). Initial evidence on the relationship between the coronavirus pandemic and crime in the united states. https: //doi.org/10.31235/osf.io/ep87s

Australian Bureau of Statistics. (2020a, May 4). Business indicators, business impacts of COVID-19, april 2020 (Cat. no. 5676.0.55.003). Australian Bureau of Statistics. Retrieved May 7, 2020, from https://www.abs.gov.au/ausstats/abs\% 40.nsf/mediareleasesbyCatalogue/49F8475B31112582CA25853600764041

Australian Bureau of Statistics. (2020b, May 1). Household impacts of COVID-19 survey, 14-17 apr 2020 (Cat. no. 4940.0 ). Australian Bureau of Statistics. Retrieved May 7, 2020, from https : / / www.abs . gov . au/ausstats/abs \% 40 . nsf/ mediareleasesbyCatalogue/DB259787916733E4CA25855B0003B21C?OpenDocument

Australian Bureau of Statistics. (2020c, May 5). Weekly payroll jobs and wages in australia, week ending 18 april 2020 (Cat. no. 6160.0.55.001) [Library Catalog: www.abs.gov.au Publisher: c=AU; o=Commonwealth of Australia; ou=Australian Bureau of Statistics]. Australian Bureau of Statistics. Library Catalog: www.abs.gov.au Publisher: $\mathrm{c}=\mathrm{AU}$; o=Commonwealth of Australia; ou=Australian Bureau of Statistics. Retrieved May 7, 2020, from https :// www.abs.gov.au/AUSSTATS/abs@.nsf/Lookup/6160.0.55.001Main+Features1Week\%20ending\%2018\%20April\% 202020? OpenDocument

Australian Government Department of Health. (2020, March 28). New and cumulative COVID-19 cases in australia by notification date [Australian government department of health]. Retrieved April 26, 2020, from https://www.health.gov.au/ resources/publications/new-and-cumulative-covid-19-cases-in-australia-by-notification-date

Brantingham, P., \& Brantingham, P. (1995). Criminality of place: Crime generators and crime attractors. European journal on criminal policy and research, 3(3), 5-26. Retrieved March 17, 2017, from http://link.springer.com/content/pdf/10. 1007/BF02242925.pdf

Campedelli, G. M., Aziani, A., \& Favarin, S. (2020). Exploring the effect of 2019-nCoV containment policies on crime: The case of los angeles. arXiv:2003.11021 [econ, q-fin, stat], arxiv 2003.11021. https://doi.org/10.31219/osf.io/gcpq8

Crime, G. I. A. T. O. (2020). Crime and contagion: The impact of a pandemic on organized crime. Global Initiative Against Transnational Organized Crime. Geneva, Switzerland. Retrieved April 25, 2020, from https://globalinitiative.net/ crime-contagion-impact-covid-crime/

Eisner, M., \& Nivette, A. (2020). Violence and the pandemic: Urgent questions for research. Harry Frank Guggenheim Foundation. New York. 
Europol. (2020). Catching the virus cybercrime, disinformation and the COVID-19 pandemic. European Union Agency for Law Enforcement Cooperation. The Hague, Netherlands. Retrieved April 25, 2020, from https://www.europol.europa.eu/ publications-documents/catching-virus-cybercrime-disinformation-and-covid-19-pandemic

Farrell, G., \& Tilley, N. (2020). Coronavirus: How crime changes during a lockdown [The conversation]. Retrieved April 25, 2020, from http://theconversation.com/coronavirus-how-crime-changes-during-a-lockdown-134948

Fitz-Gibbon, K., \& Meyer, S. (2020, March 18). Coronavirus: Fear of family violence spike as COVID-19 impact hits households [Lens: Pioneering research stories, commentary and opinion told by leading academics - monash university]. Retrieved April 25, 2020, from https://lens.monash.edu/@ politics-society/2020/03/18/1379841?slug=coronavirusfear-of-family-violence-spike-as-covid-19-impact-hits-households

Gerell, M., Kardell, J., \& Kindgren, J. (2020). Minor covid-19 association with crime in sweden, a five week follow up. https: //doi.org/10.31235/osf.io/w7gka

Google. (2020, April 26). COVID-19 community mobility report [Google]. Retrieved April 27, 2020, from https://www.google. com/covid19/mobility

Kinner, S. A., Young, J. T., Snow, K., Southalan, L., Lopez-Acuña, D., Ferreira-Borges, C., \& O’Moore, É. (2020). Prisons and custodial settings are part of a comprehensive response to COVID-19 [Publisher: Elsevier]. The Lancet Public Health, 5(4), e188-e189. https://doi.org/10.1016/S2468-2667(20)30058-X

Lum, C., Maupin, C., \& Stoltz, M. (2020, April 13). The impact of COVID-19 on law enforcement agencies (wave 1). International Association of Chiefs of Police and the Center for Evidence-Based Crime Policy, George Mason University. Washington, D.C.

Midoes, C. (2020, April 7). Social distancing: Did individuals act before governments? Retrieved April 25, 2020, from https: //www.bruegel.org/2020/04/social-distancing-did-individuals-act-before-governments/

Mohler, G., Bertozzi, A. L., Carter, J., Short, M. B., Sledge, D., Tita, G. E., Uchida, C. D., \& Brantingham, P. J. (2020). Impact of social distancing during COVID-19 pandemic on crime in los angeles and indianapolis. Journal of Criminal Justice, 101692. https://doi.org/10.1016/j.jcrimjus.2020.101692

Nivette, A., Ribeaud, D., Murray, A. L., Steinhoff, A., Bechtiger, L., Hepp, U., Shanahan, L., \& Eisner, M. (2020). Noncompliance with COVID-19-related public health measures among young adults: Insights from a longitudinal cohort study. https://doi.org/10.31235/osf.io/8edbj

Queensland Government. (2020, April 30). Queensland offence rates - open data portal [SBS]. Retrieved April 30, 2020, from https://www.data.qld.gov.au/dataset/offence-rates-monthly-from-july-1997

Reynald, D. M., \& Elffers, H. (2015). The routine activity of guardianship: Comparing self-reports of guardianship intensity patterns with proxy measures. Crime Prevention and Community Safety, 17(4), 211-232. https://doi.org/10.1057/cpcs. 2015.9

Rossner, M., \& Tait, D. (2020, April 8). Courts are moving to video during coronavirus, but research shows it's hard to get a fair trial remotely [The conversation] [Library Catalog: theconversation.com]. Retrieved April 29, 2020, from http://theconversation.com/courts-are-moving-to-video-during-coronavirus-but-research-shows-its-hard-to-get-afair-trial-remotely- 134386

Sarat, A. (2020, March 19). Coronavirus: Will courts continue to operate, preserving the rule of law? [The conversation] [Library Catalog: theconversation.com]. Retrieved April 29, 2020, from http://theconversation.com/coronavirus-willcourts-continue-to-operate-preserving-the-rule-of-law-134084

van Gelder, N., Peterman, A., Potts, A., O’Donnell, M., Thompson, K., Shah, N., \& Oertelt-Prigione, S. (2020). COVID19: Reducing the risk of infection might increase the risk of intimate partner violence [Publisher: Elsevier]. EClinicalMedicine, O(0). https://doi.org/10.1016/j.eclinm.2020.100348

World Health Organization. (2020, January 30). WHO director-general's statement on IHR emergency committee on novel coronavirus (2019-nCoV) [World health organization] [Library Catalog: www.who.int]. Retrieved April 29, 2020, from https://www.who.int/dg/speeches/detail/who-director-general-s-statement-on-ihr-emergency-committee-onnovel-coronavirus-(2019-ncov) 


\section{List of Figures}

1 New and cumulative confirmed COVID-19 cases by notification date . . . . . . . . . . . . . . 16

2 Changes in mobility over time, Australia, 15 February - 17 April . . . . . . . . . . . . . . . . . 17

3 Changes in mobility (as at 31 March 2020), by location type . . . . . . . . . . . . . . . 18

4 Long-term PROPERTY DAMAGE rate forecasts (actual rates and ARIMA forecasts) . . . . . . . . . . . . . 19

5 Short-term PROPERTY DAMAGE rates (actual rates and ARIMA forecasts) . . . . . . . . . . . . . . . . 20

6 Long-term SHOP STEALING rate forecasts (actual rates and ARIMA forecasts) . . . . . . . . . . . . . . . 21

7 Short-term SHOP STEALING rates (actual rates and ARIMA forecasts) . . . . . . . . . . . . . . . . 22

8 Long-term OTHER THEFT rate forecasts (actual rates and ARIMA forecasts) . . . . . . . . . . . . . 23

9 Short-term OTHER THEFT rate forecasts (actual rates and ARIMA forecasts) . . . . . . . . . . . . . . . . 24

10 Long-term BURGLARY rate forecasts (actual rates and ARIMA forecasts) . . . . . . . . . . . . . . . . . 25

11 Short-term BURGLARY rate forecasts (actual rates and ARIMA forecasts) . . . . . . . . . . . . . . . 26

12 Long-term MOTOR VEHICLE THEFT rate forecasts (actual rates and ARIMA forecasts) . . . . . . . . . . . 27

13 Short-term MOTOR VEHICLE THEFT rate forecasts (actual rates and ARIMA forecasts) . . . . . . . . . . . 28

14 Long-term FRAUD rate forecasts (actual rates and ARIMA forecasts) . . . . . . . . . . . . . . . . . . 29

15 Short-term FRAUD rate forecasts (actual rates and ARIMA forecasts) . . . . . . . . . . . . . . . . 30

16 Long-term CREDIT CARD FRAUD rate forecasts (actual rates and ARIMA forecasts) . . . . . . . . . . 31

17 Short-term CREDIT CARD FRAUD rate forecasts (actual rates and ARIMA forecasts) . . . . . . . . . . . 32 
Figure 1: New and cumulative confirmed COVID-19 cases by notification date new cases

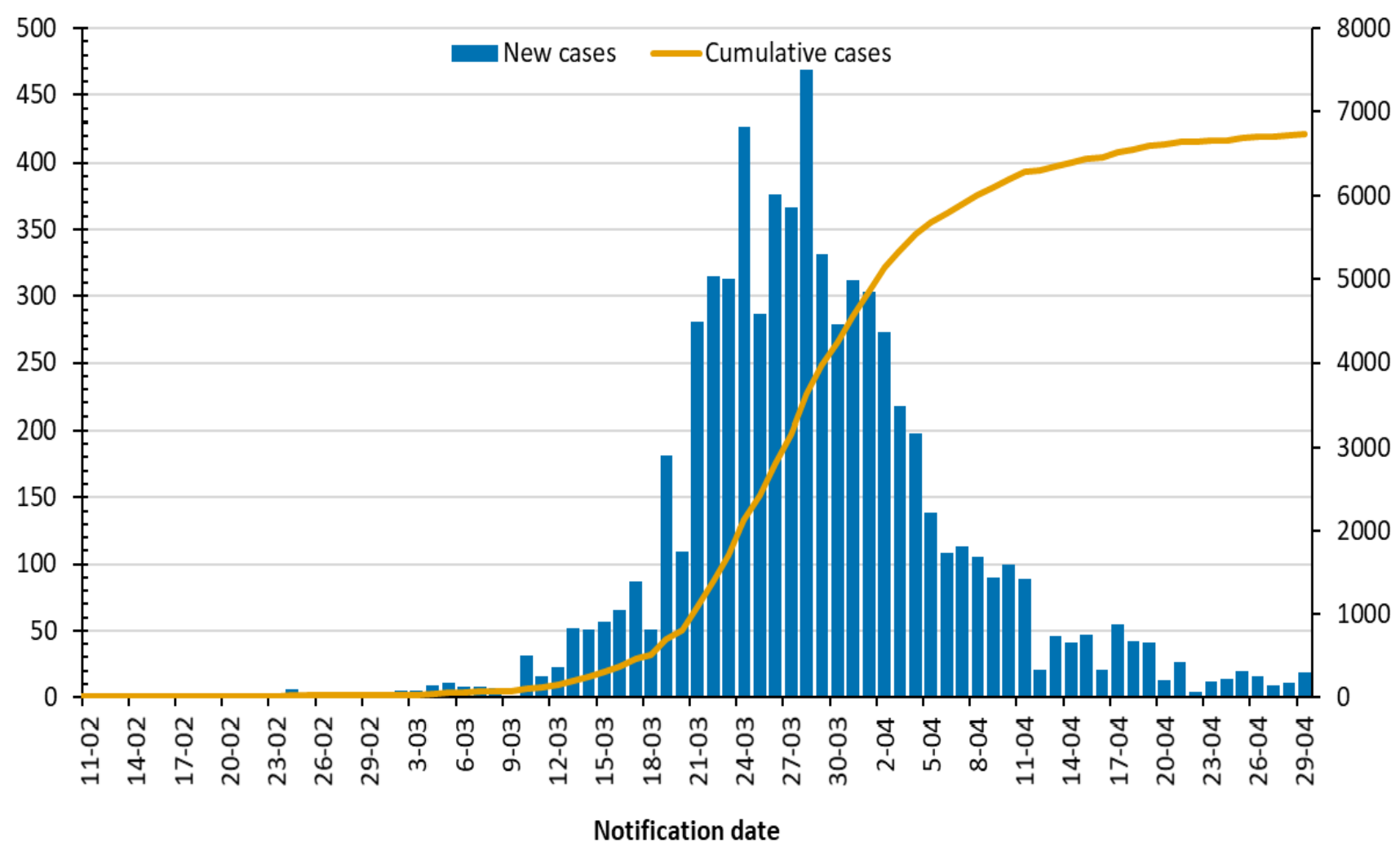

Source: Australian Government Department of Health, 2020b 
Figure 2: Changes in mobility over time, Australia, 15 February - 17 April

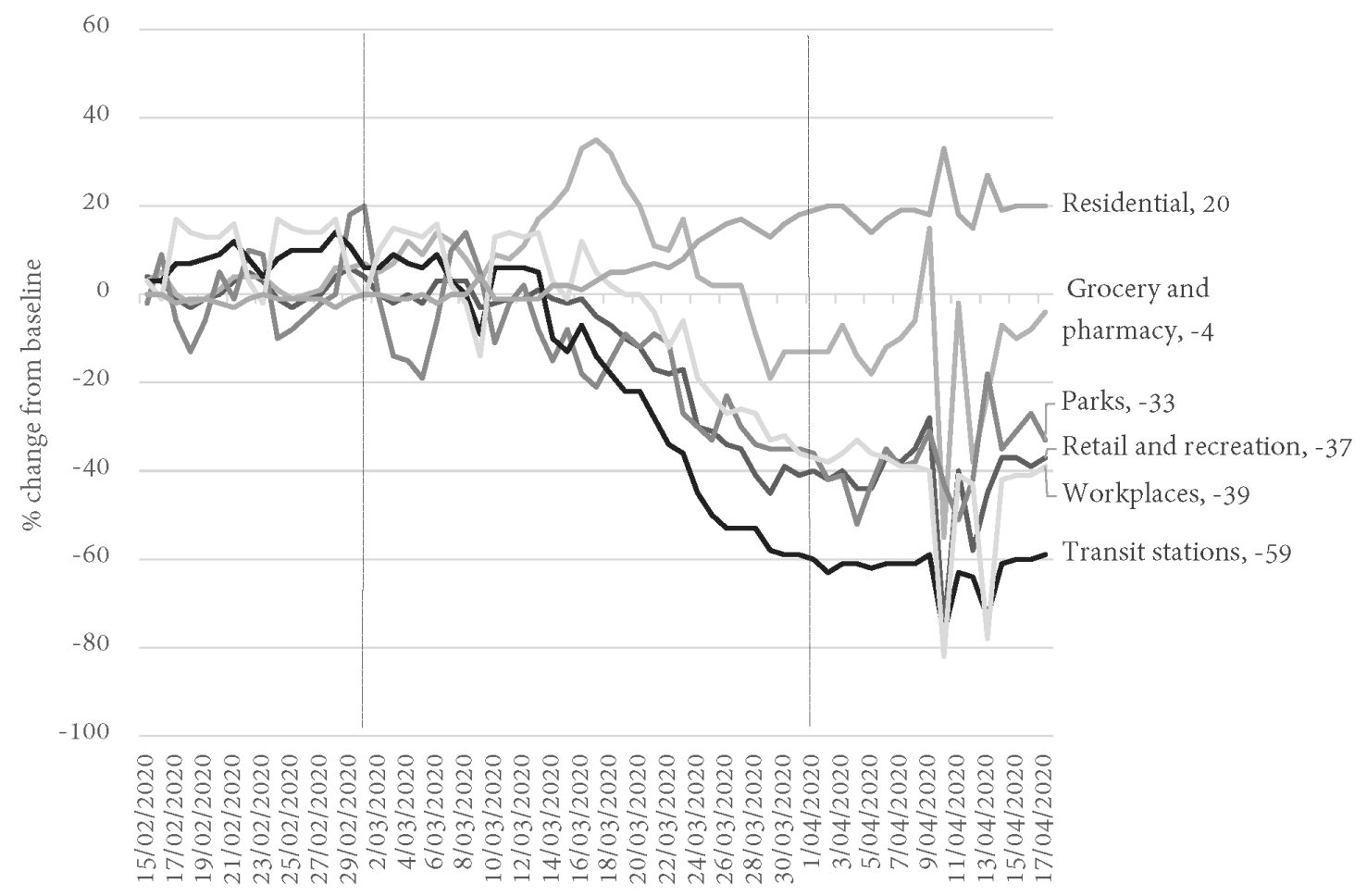

Source: Google COVID-19 Community Mobility Report 
Figure 3: Changes in mobility (as at 31 March 2020), by location type

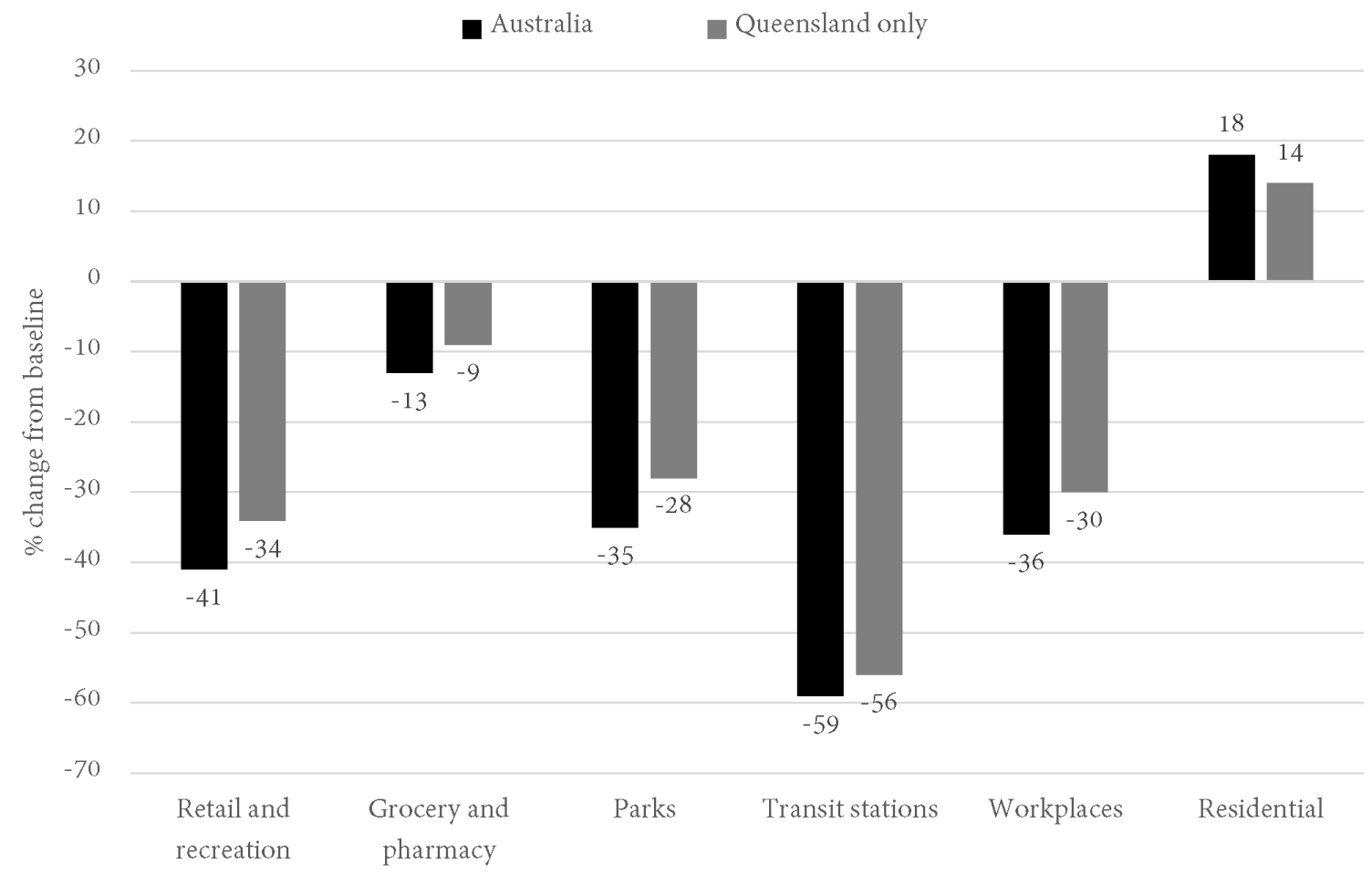

Source: Google COVID-19 Community Mobility Report 
Figure 4: Long-term PROPERTY DAMAGE rate forecasts (actual rates and ARIMA forecasts)

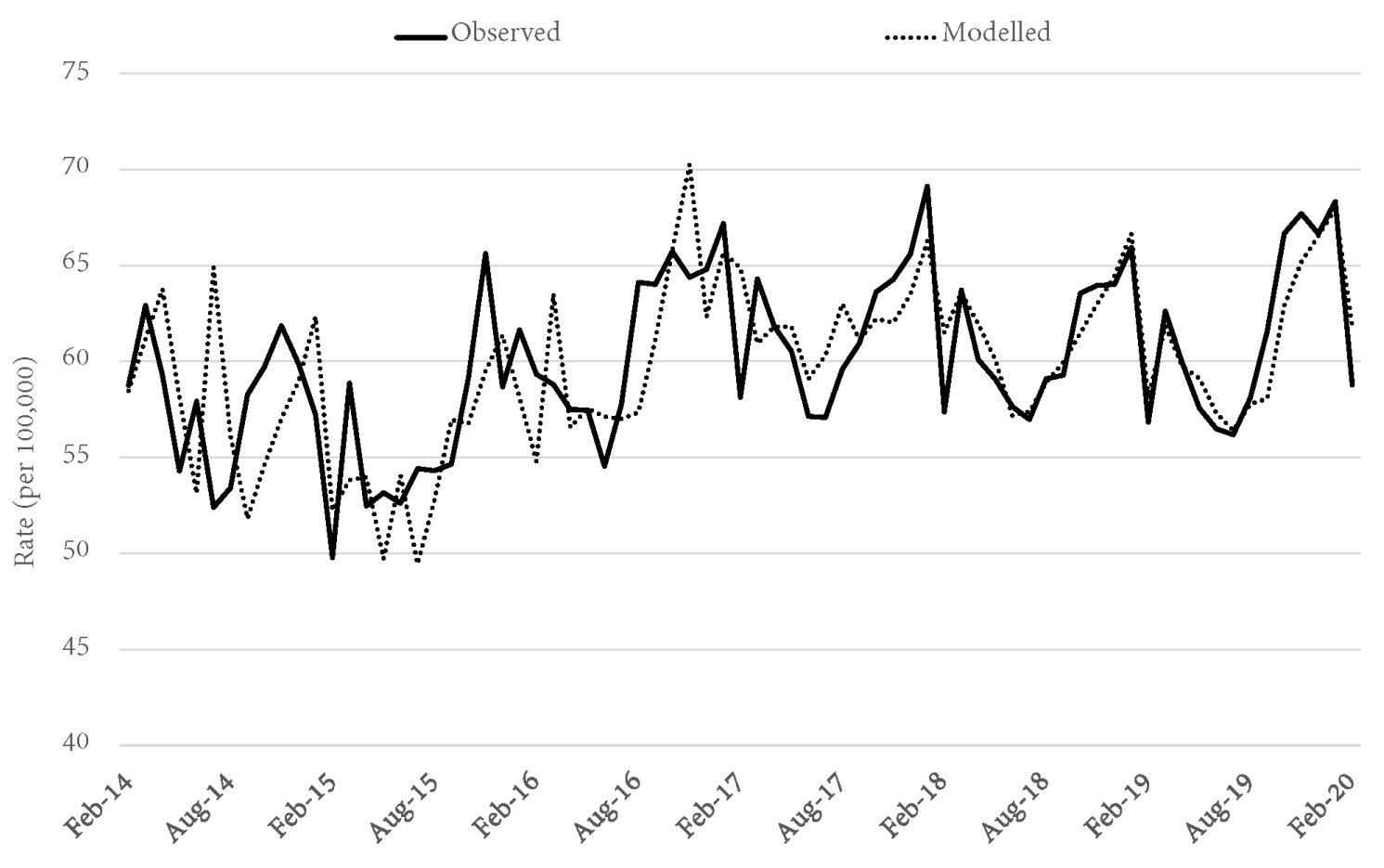

Source: Queensland offence rates, Open Data Portal 
Figure 5: Short-term PROPERTY DAMAGE rates (actual rates and ARIMA forecasts)

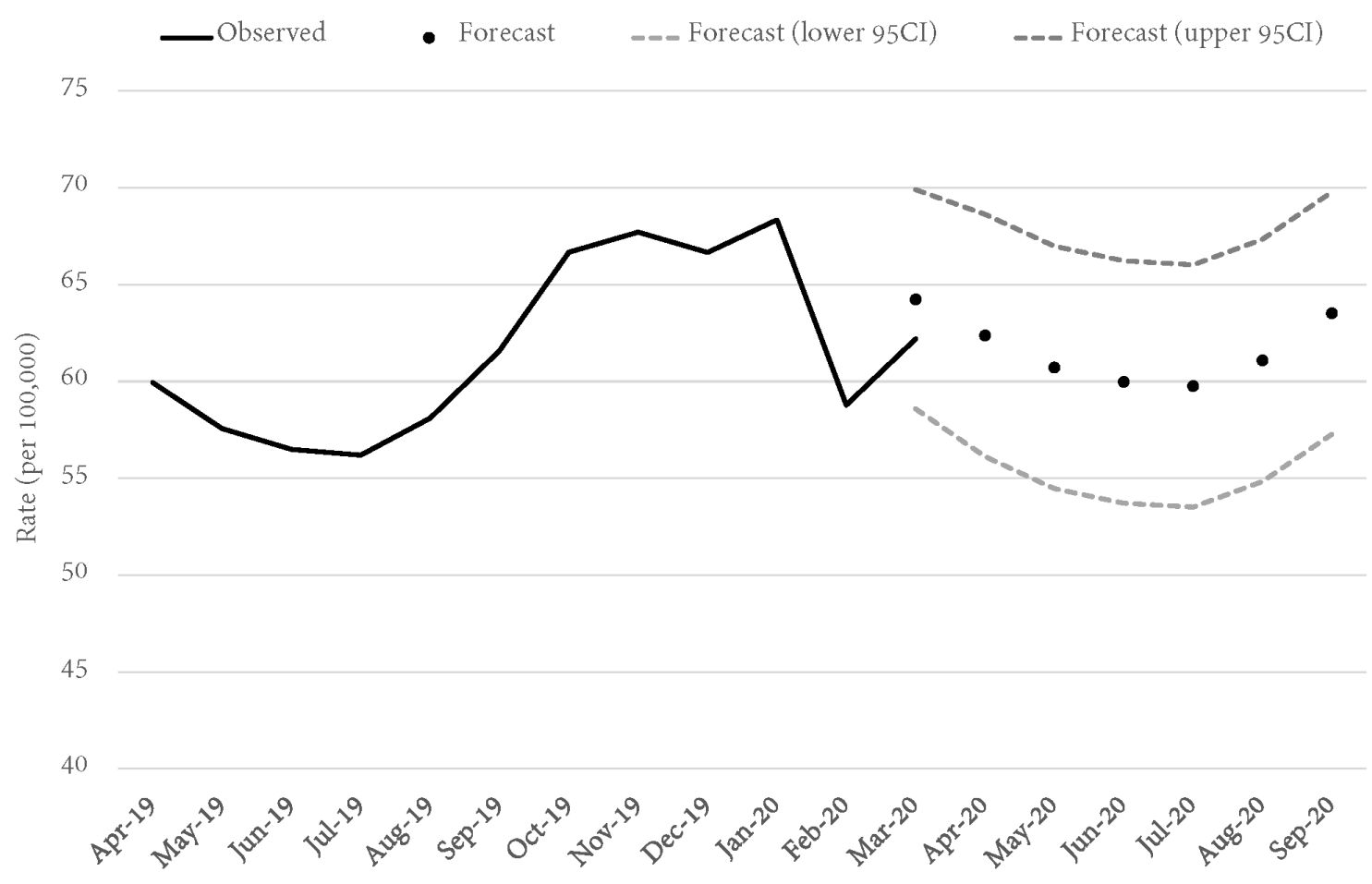

Source: Queensland offence rates, Open Data Portal 
Figure 6: Long-term SHOP STEALING rate forecasts (actual rates and ARIMA forecasts)

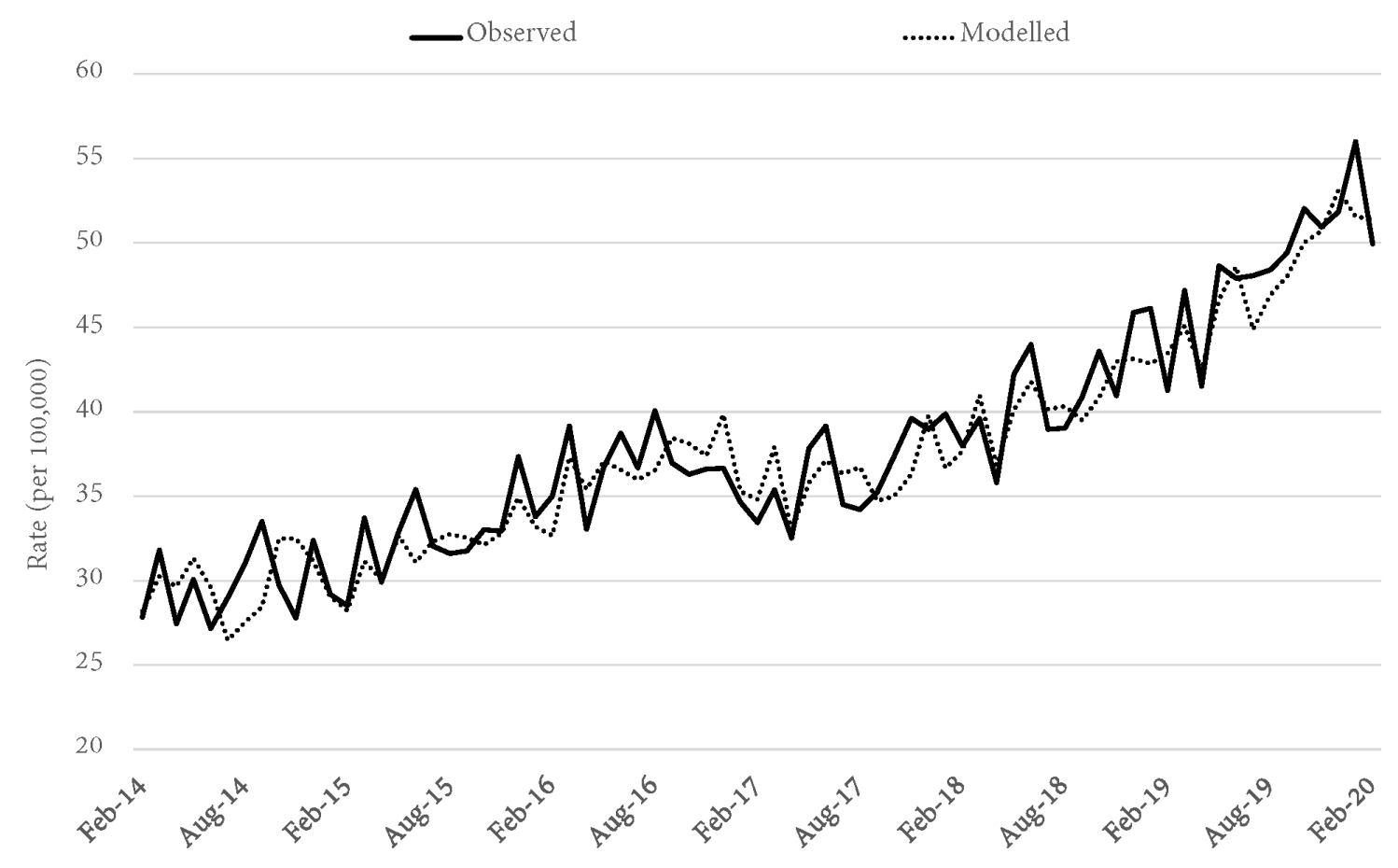

Source: Queensland offence rates, Open Data Portal 
Figure 7: Short-term SHOP STEALING rates (actual rates and ARIMA forecasts)

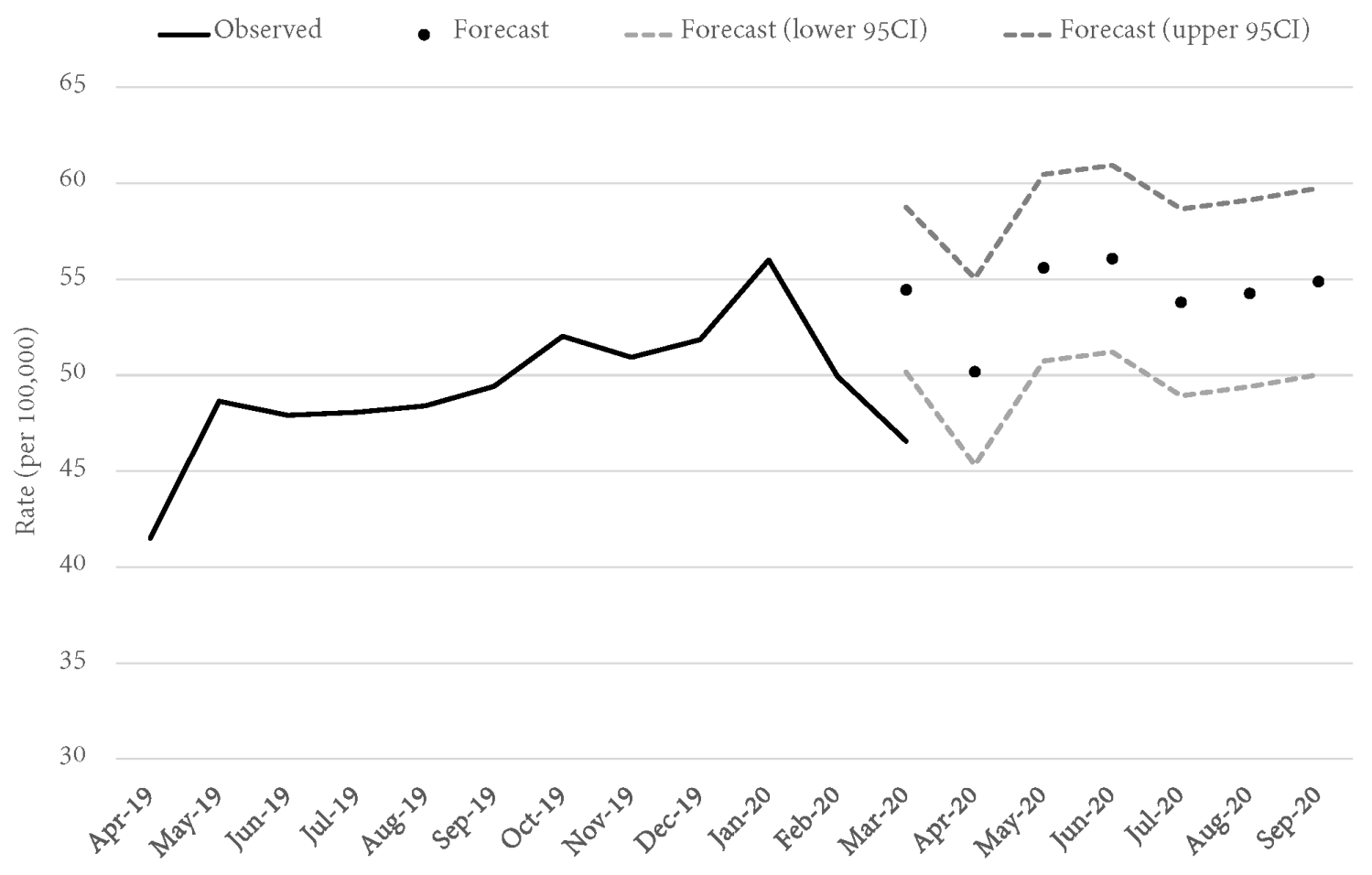

Source: Queensland offence rates, Open Data Portal 
Figure 8: Long-term OTHER THEFT rate forecasts (actual rates and ARIMA forecasts)

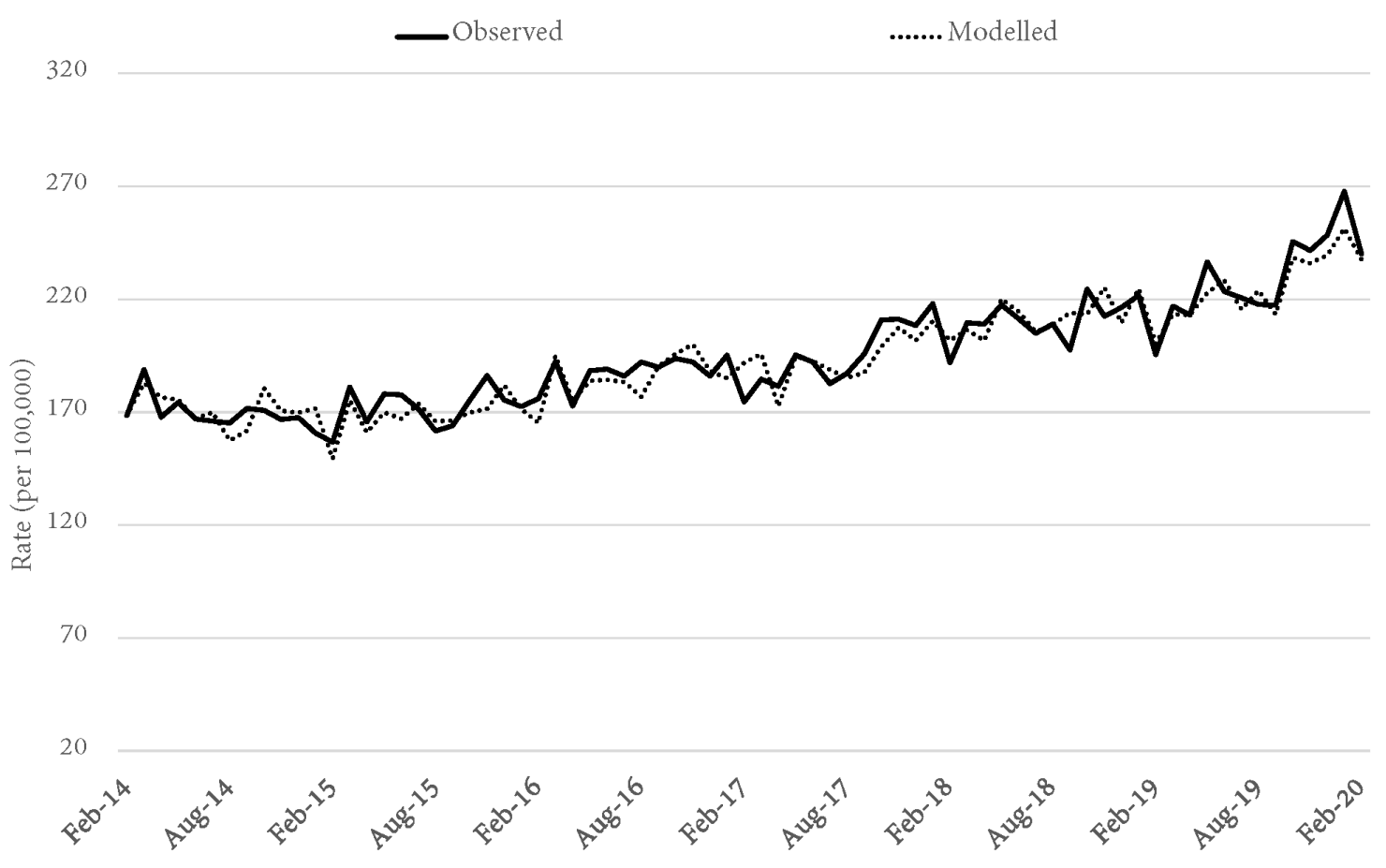

Source: Queensland offence rates, Open Data Portal 
Figure 9: Short-term OTHER THEFT rate forecasts (actual rates and ARIMA forecasts)

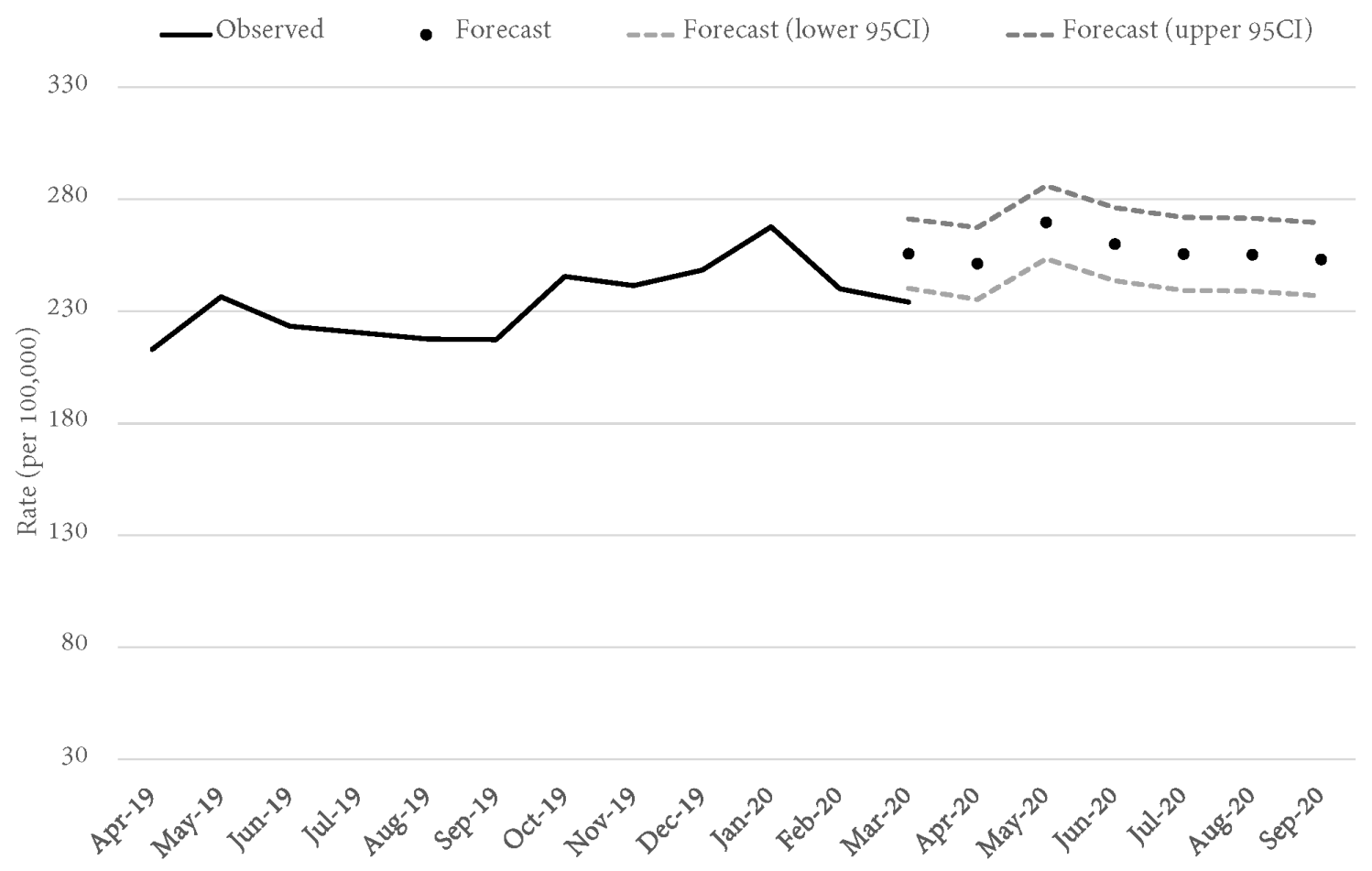

Source: Queensland offence rates, Open Data Portal 
Figure 10: Long-term BURGLARY rate forecasts (actual rates and ARIMA forecasts)

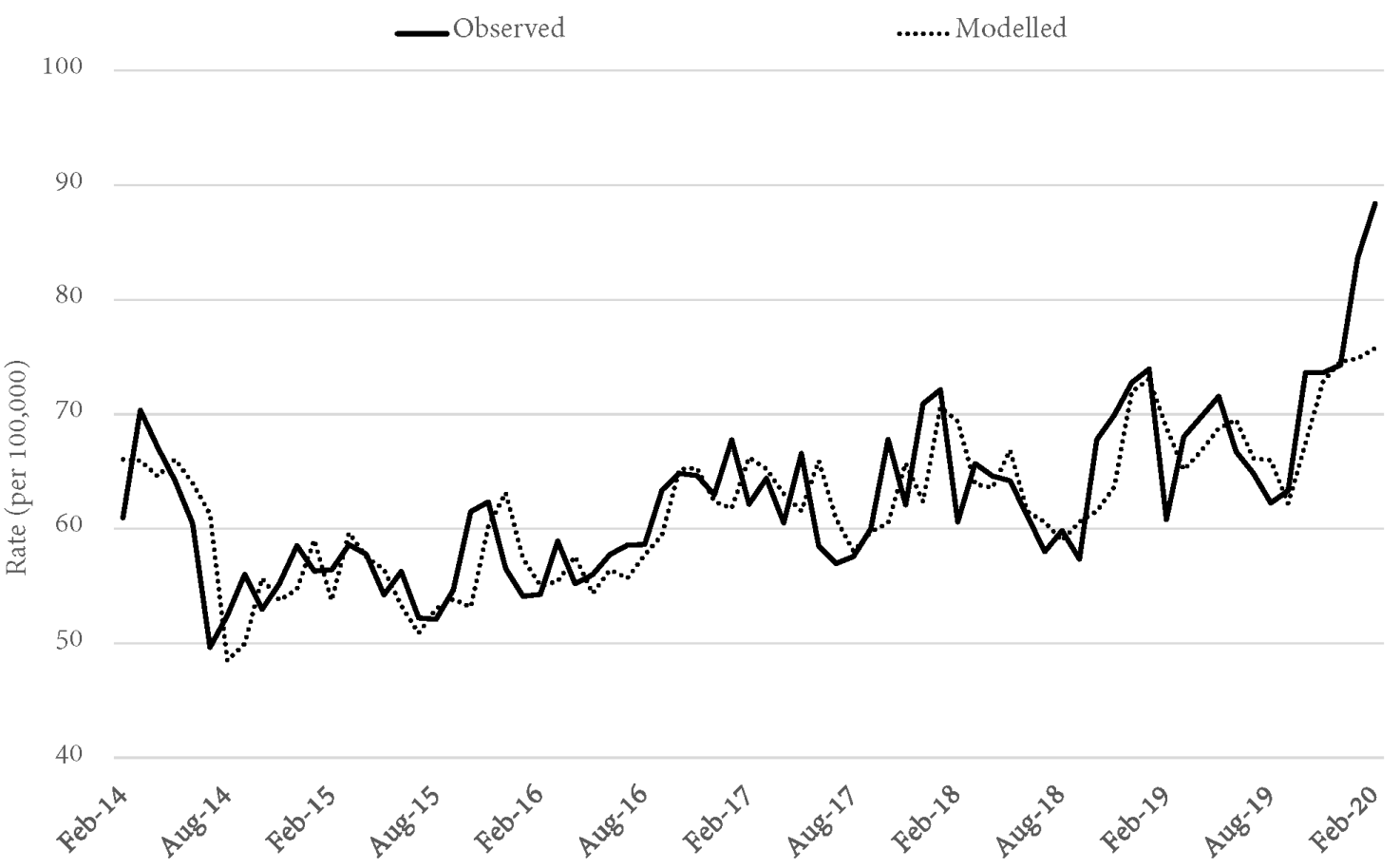

Source: Queensland offence rates, Open Data Portal 
Figure 11: Short-term BURGLARY rate forecasts (actual rates and ARIMA forecasts)

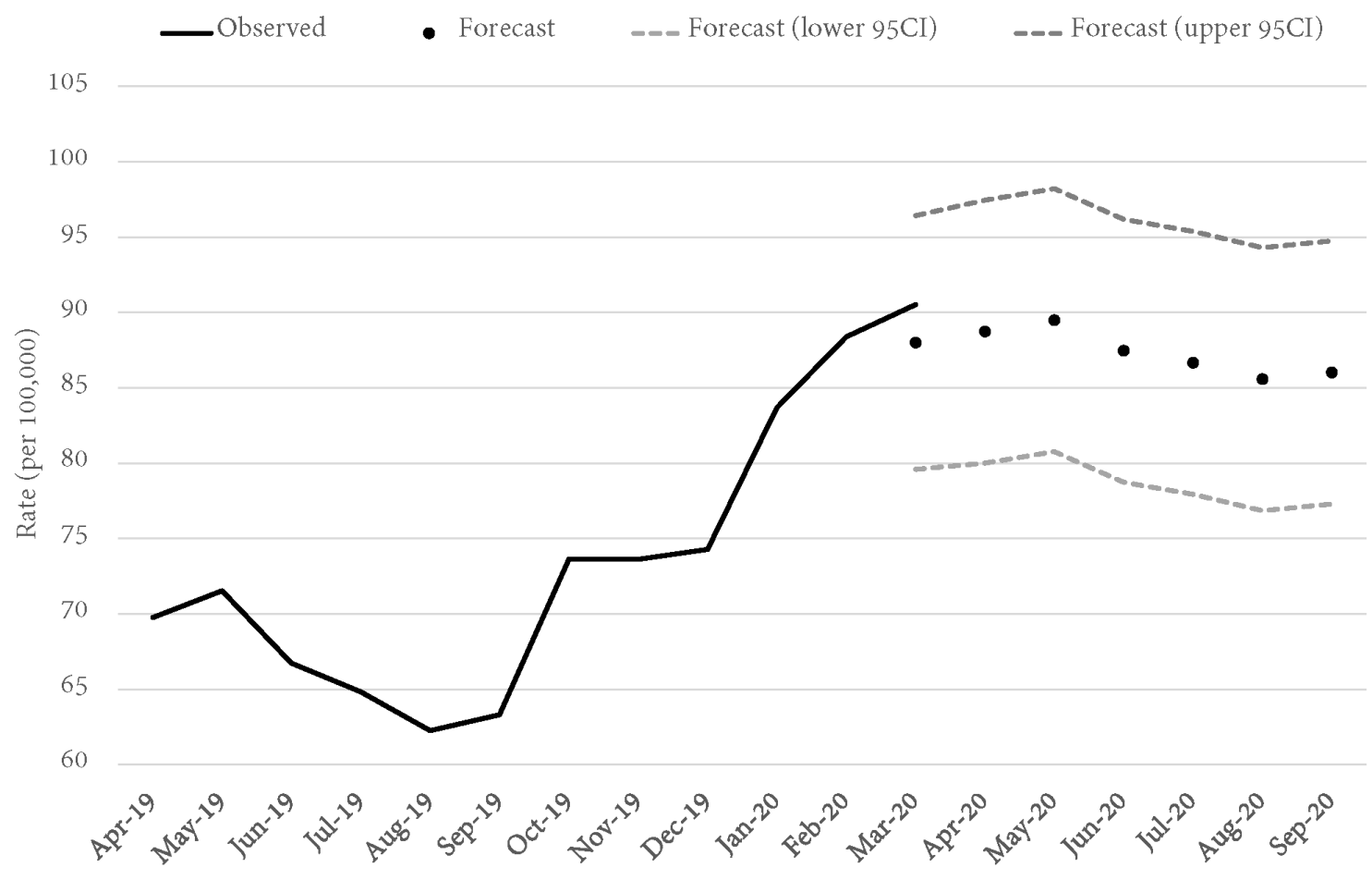

Source: Queensland offence rates, Open Data Portal 
Figure 12: Long-term MOTOR VEHICLE THEFT rate forecasts (actual rates and ARIMA forecasts)

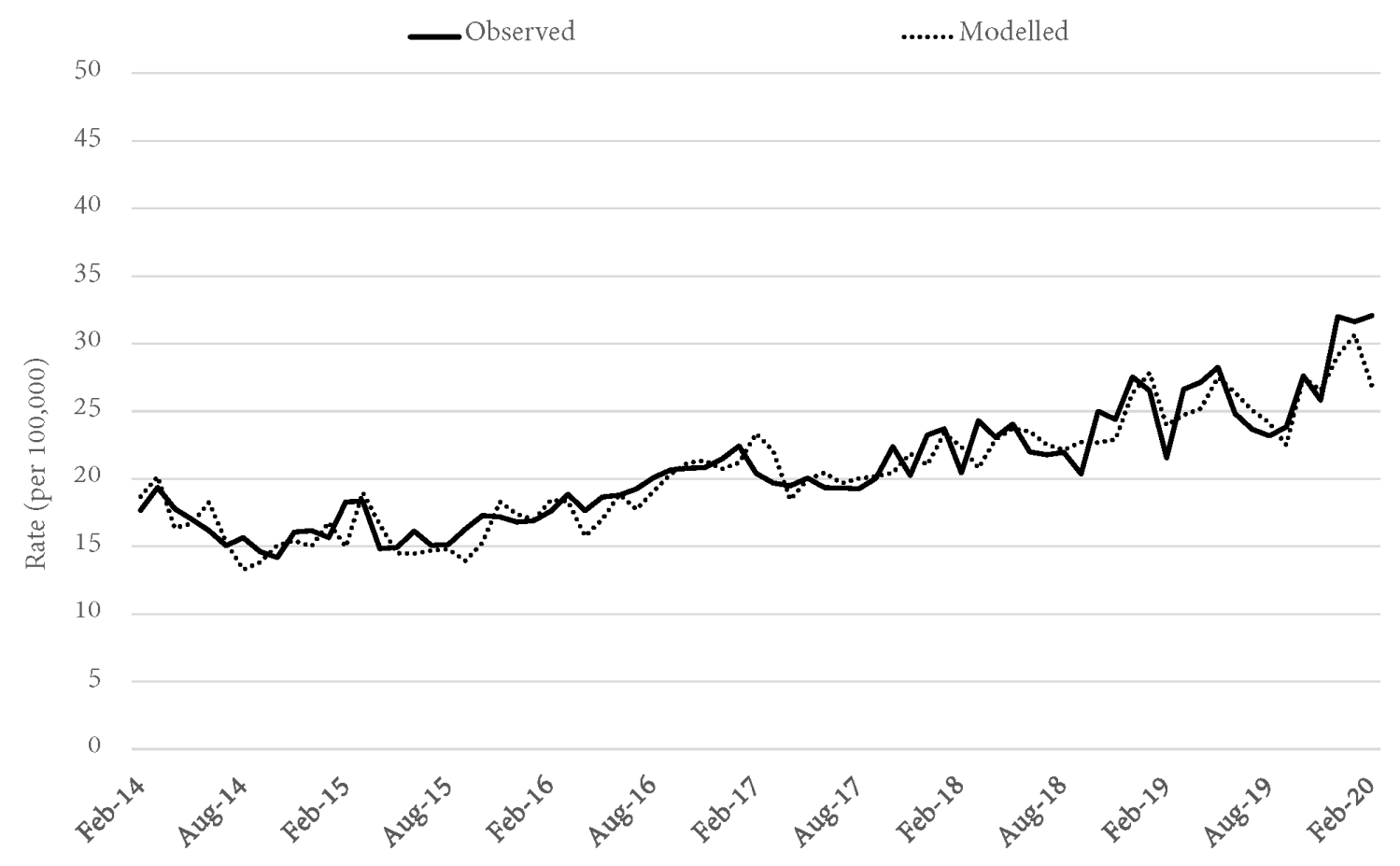

Source: Queensland offence rates, Open Data Portal 
Figure 13: Short-term MOTOR VEHICLE THEFT rate forecasts (actual rates and ARIMA forecasts)

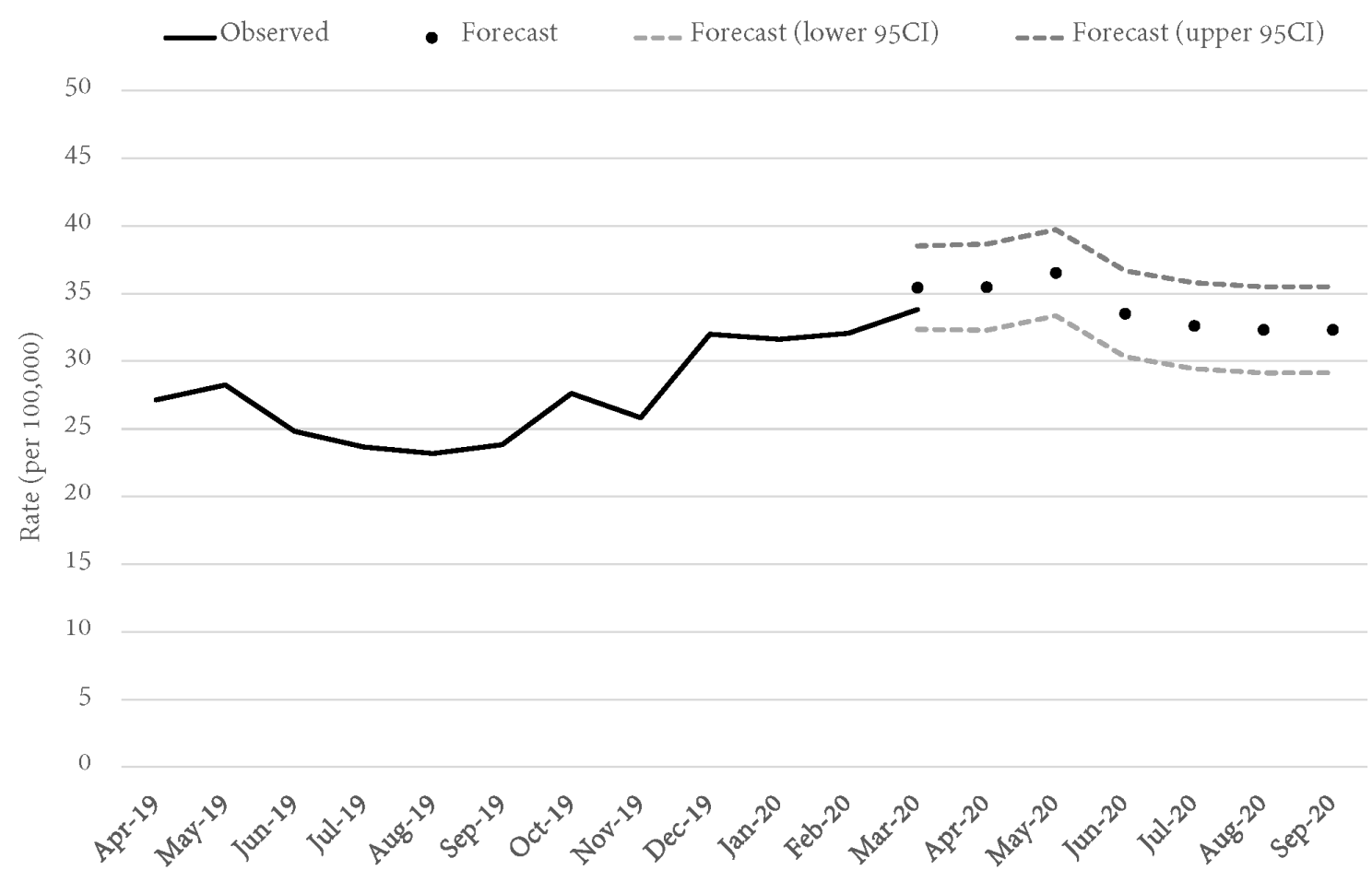

Source: Queensland offence rates, Open Data Portal 
Figure 14: Long-term FRAUD rate forecasts (actual rates and ARIMA forecasts)

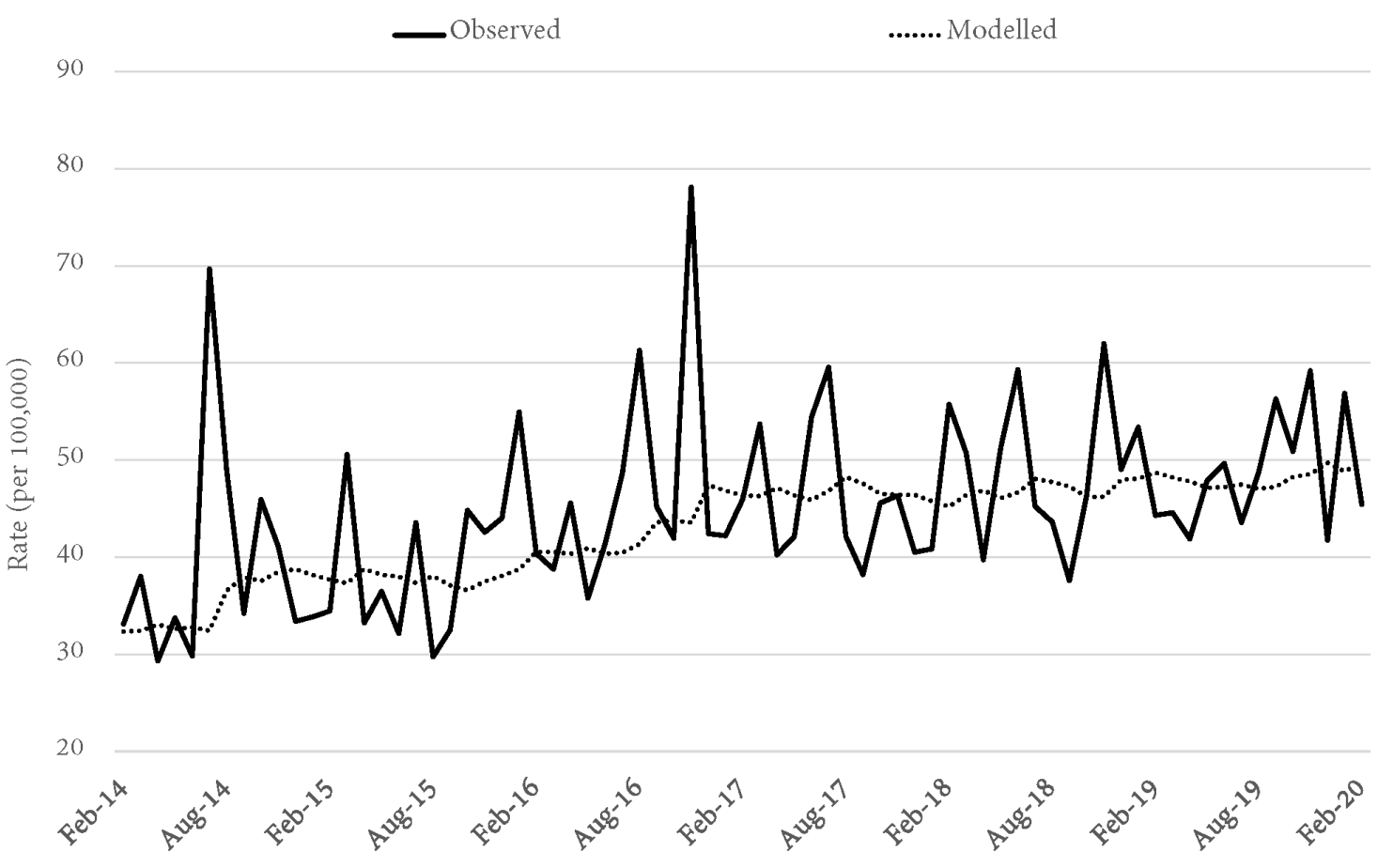

Source: Queensland offence rates, Open Data Portal 
Figure 15: Short-term FRAUD rate forecasts (actual rates and ARIMA forecasts)

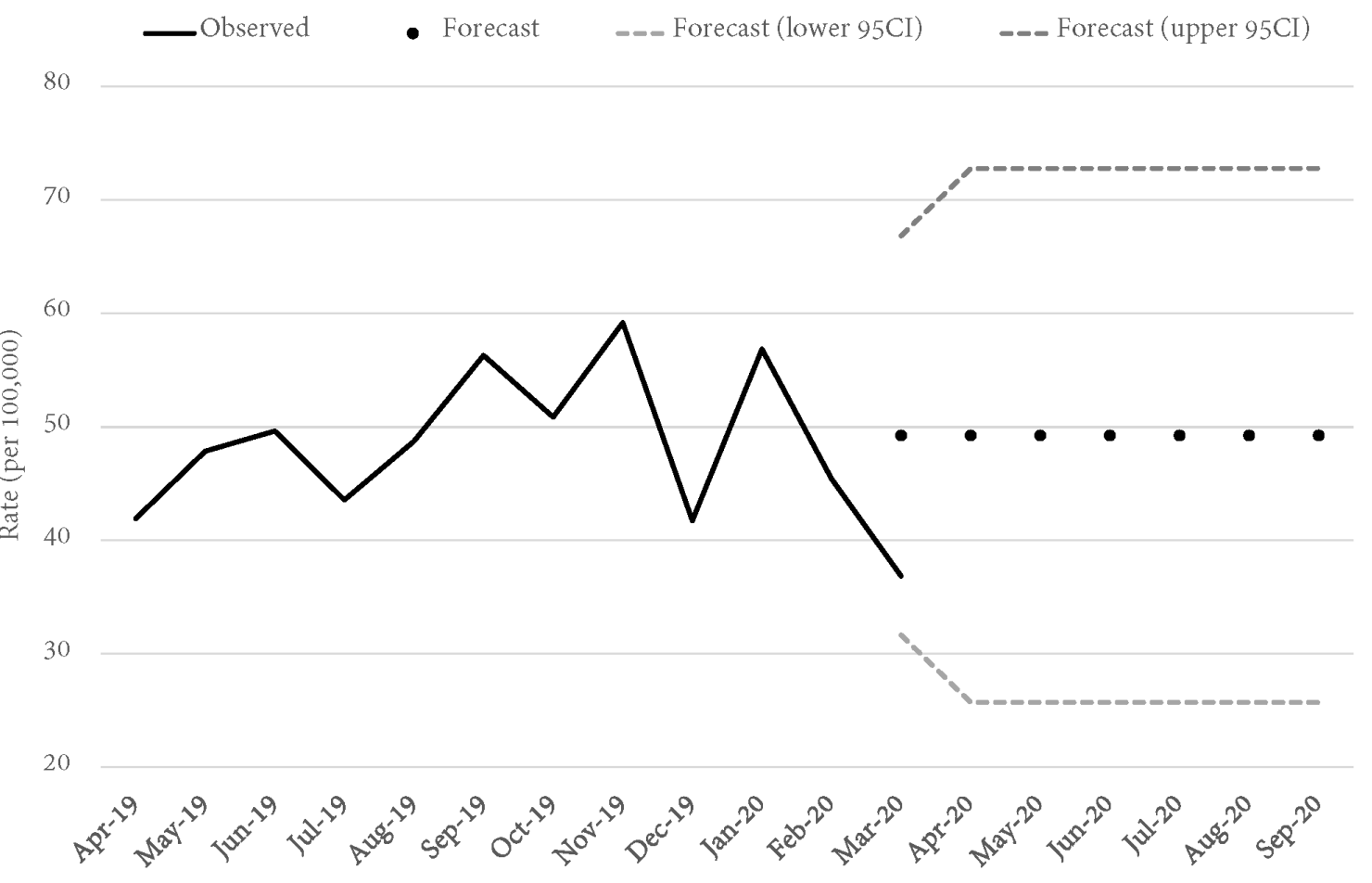

Source: Queensland offence rates, Open Data Portal 
Figure 16: Long-term CREDIT CARD FRAUD rate forecasts (actual rates and ARIMA forecasts)

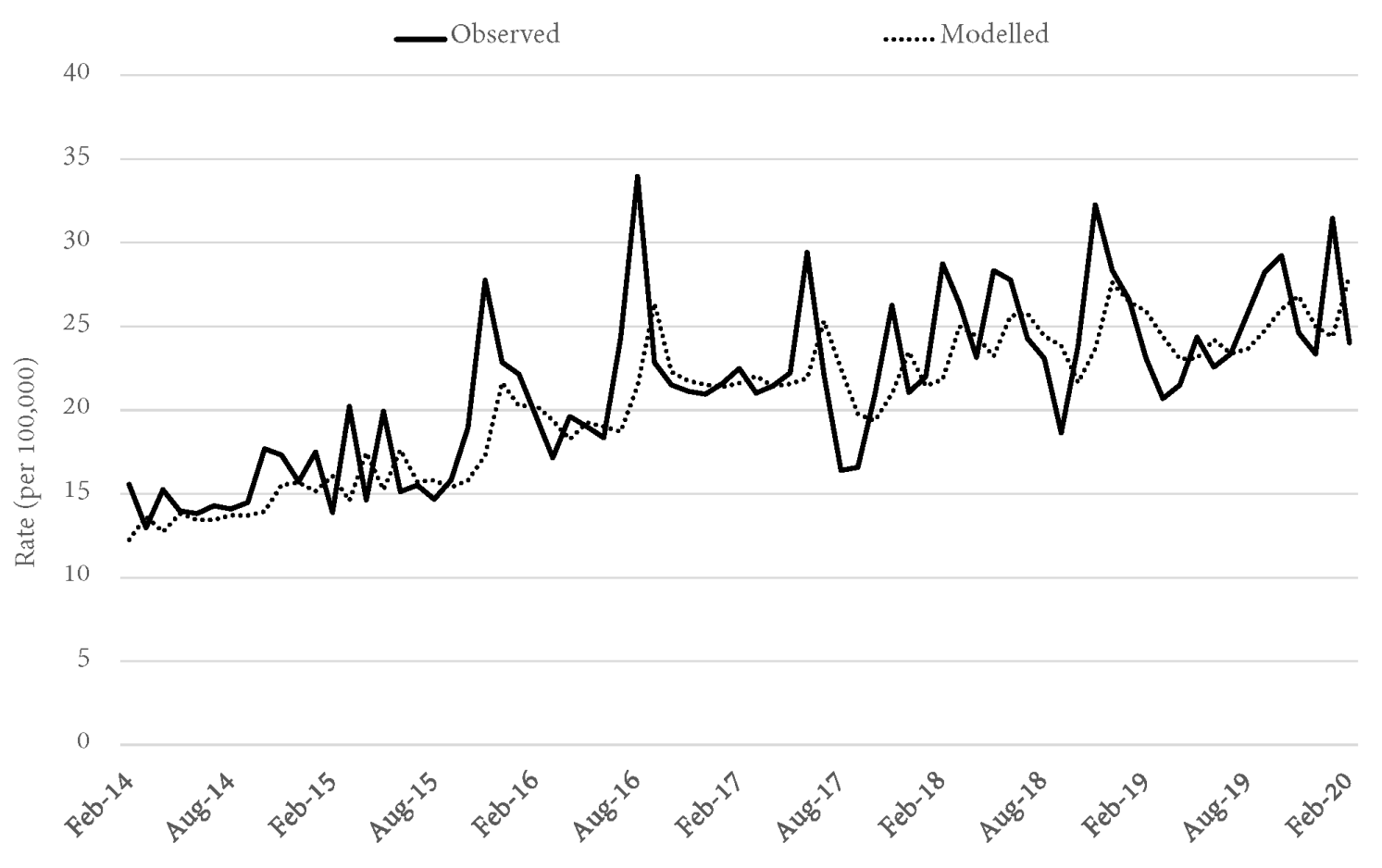

Source: Queensland offence rates, Open Data Portal 
Figure 17: Short-term CREDIT CARD FRAUD rate forecasts (actual rates and ARIMA forecasts)

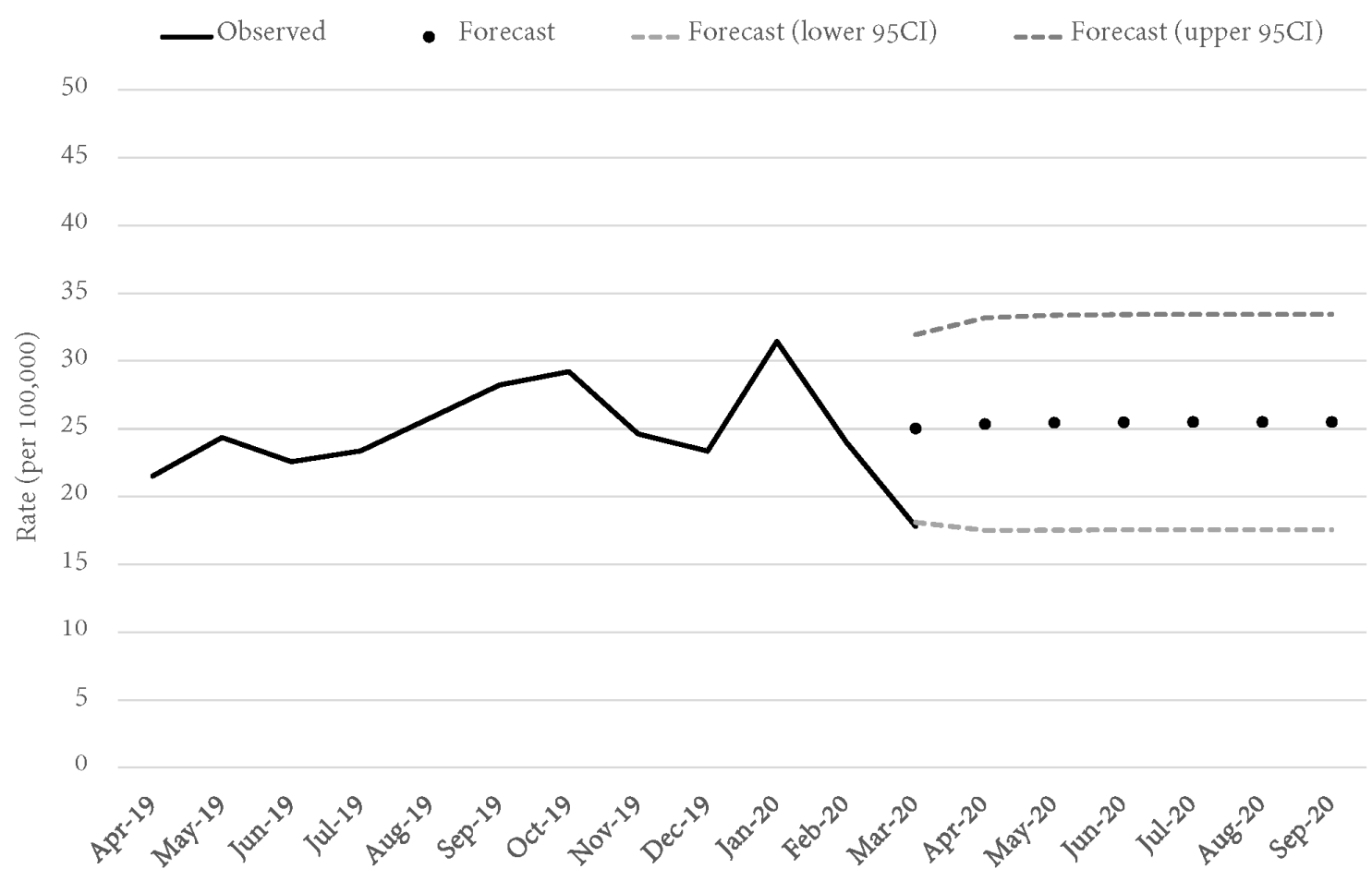

Source: Queensland offence rates, Open Data Portal 